\title{
Clinician-targeted interventions to influence antibiotic prescribing behaviour for acute respiratory infections in primary care: an overview of systematic reviews (Review)
}

Tonkin-Crine SKG, Tan PS, van Hecke O, Wang K, Roberts NW, McCullough A, Hansen MP, Butler CC, Del Mar CB

Tonkin-Crine SKG, Tan PS, van Hecke O, Wang K, Roberts NW, McCullough A, Hansen MP, Butler CC, Del Mar CB.

Clinician-targeted interventions to influence antibiotic prescribing behaviour for acute respiratory infections in primary care: an overview of systematic reviews.

Cochrane Database of Systematic Reviews 2017, Issue 9. Art. No.: CD012252.

DOI: 10.1002/14651858.CD012252.pub2.

www.cochranelibrary.com

Clinician-targeted interventions to influence antibiotic prescribing behaviour for acute respiratory infections in primary care: an overview of systematic reviews (Review) 
HEADER 1

ABSTRACT

PLAIN LANGUAGE SUMMARY

BACKGROUND

OBJECTIVES

METHODS

RESULTS

Figure 1.

DISCUSSION

AUTHORS' CONCLUSIONS

ACKNOWLEDGEMENTS

REFERENCES

ADDITIONAL TABLES

APPENDICES

WHAT'S NEW

HISTORY

CONTRIBUTIONS OF AUTHORS

DECLARATIONS OF INTEREST

SOURCES OF SUPPORT

INDEX TERMS

\section{TABLE OF CONTENTS}


[Overview of Reviews]

\section{Clinician-targeted interventions to influence antibiotic prescribing behaviour for acute respiratory infections in primary care: an overview of systematic reviews}

Sarah KG Tonkin-Crineㄹ, Pui San Tan ${ }^{1}$, Oliver van Hecke¹, Kay Wang ${ }^{1}$, Nia W Roberts ${ }^{2}$, Amanda McCullough ${ }^{3}$, Malene Plejdrup Hansen ${ }^{4}$, Christopher C Butler ${ }^{1}$, Chris B Del Mar ${ }^{3}$

${ }^{1}$ Nuffield Department of Primary Care Health Sciences, University of Oxford, Oxford, UK. ${ }^{2}$ Bodleian Health Care Libraries, University of Oxford, Oxford, UK. ${ }^{3}$ Centre for Research in Evidence-Based Practice (CREBP), Bond University, Gold Coast, Australia. ${ }^{4}$ Center for General Practice at Aalborg University, Aalborg, Denmark

Contact address: Sarah KG Tonkin-Crine, Nuffield Department of Primary Care Health Sciences, University of Oxford, Woodstock Road, Oxford, Oxon, OX2 6GG, UK. sarah.tonkin-crine@phc.ox.ac.uk.

Editorial group: Cochrane Acute Respiratory Infections Group.

Publication status and date: Edited (no change to conclusions), published in Issue 9, 2019.

Citation: Tonkin-Crine SKG, Tan PS, van Hecke O, Wang K, Roberts NW, McCullough A, Hansen MP, Butler CC, Del Mar CB. Cliniciantargeted interventions to influence antibiotic prescribing behaviour for acute respiratory infections in primary care: an overview of systematic reviews. Cochrane Database of Systematic Reviews 2017, Issue 9. Art. No.: CD012252. DOI: 10.1002/14651858.CD012252.pub2.

Copyright @ 2019 The Cochrane Collaboration. Published by John Wiley \& Sons, Ltd.

\section{A B S T R A C T}

\section{Background}

Antibiotic resistance is a worldwide health threat. Interventions that reduce antibiotic prescribing by clinicians are expected to reduce antibiotic resistance. Disparate interventions to change antibiotic prescribing behaviour for acute respiratory infections (ARIs) have been trialled and meta-analysed, but not yet synthesised in an overview. This overview synthesises evidence from systematic reviews, rather than individual trials.

\section{Objectives}

To systematically review the existing evidence from systematic reviews on the effects of interventions aimed at influencing clinician antibiotic prescribing behaviour for ARIs in primary care.

\section{Methods}

We searched the Cochrane Database of Systematic Reviews, Database of Abstracts of Reviews of Effects (DARE), MEDLINE, Embase, CINAHL, PsycINFO, and Science Citation Index to June 2016. We also searched the reference lists of all included reviews. We ran a pre-publication search in May 2017 and placed additional studies in 'awaiting classification'.

We included both Cochrane and non-Cochrane reviews of randomised controlled trials evaluating the effect of any clinician-focussed intervention on antibiotic prescribing behaviour in primary care. Two overview authors independently extracted data and assessed the methodological quality of included reviews using the ROBIS tool, with disagreements reached by consensus or by discussion with a third overview author. We used the GRADE system to assess the quality of evidence in included reviews. The results are presented as a narrative overview.

\section{Main results}

We included eight reviews in this overview: five Cochrane Reviews (33 included trials) and three non-Cochrane reviews (11 included trials). Three reviews (all Cochrane Reviews) scored low risk across all the ROBIS domains in Phase 2 and low risk of bias overall. The remaining five reviews scored high risk on Domain 4 of Phase 2 because the 'Risk of bias' assessment had not been specifically considered and discussed 
in the review Results and Conclusions. The trials included in the reviews varied in both size and risk of bias. Interventions were compared to usual care.

Moderate-quality evidence indicated that C-reactive protein (CRP) point-of-care testing (risk ratio (RR) $0.78,95 \%$ confidence interval (CI) 0.66 to $0.92,3284$ participants, 6 trials), shared decision making (odds ratio (OR) $0.44,95 \% \mathrm{Cl} 0.26$ to 0.75 , 3274 participants, 3 trials; RR $0.64,95 \% \mathrm{Cl} 0.49$ to $0.84,4623$ participants, 2 trials; risk difference $-18.44,95 \% \mathrm{Cl}-27.24$ to $-9.65,481,807$ participants, 4 trials), and procalcitonin-guided management (adjusted OR $0.10,95 \% \mathrm{Cl} 0.07$ to $0.14,1008$ participants, 2 trials) probably reduce antibiotic prescribing in general practice. We found moderate-quality evidence that procalcitonin-guided management probably reduces antibiotic prescribing in emergency departments (adjusted OR $0.34,95 \% \mathrm{Cl} 0.28$ to $0.43,2605$ participants, 7 trials). The overall effect of these interventions was small (few achieving greater than $50 \%$ reduction in antibiotic prescribing, most about a quarter or less), but likely to be clinically important.

Compared to usual care, shared decision making probably makes little or no difference to reconsultation for the same illness (RR 0.87 , $95 \% \mathrm{Cl} 0.74$ to $1.03,1860$ participants, 4 trials, moderate-quality evidence), and may make little or no difference to patient satisfaction (RR $0.86,95 \% \mathrm{Cl} 0.57$ to $1.30,1110$ participants, 2 trials, low-quality evidence). Similarly, CRP testing probably has little or no effect on patient satisfaction (RR $0.79,95 \% \mathrm{Cl} 0.57$ to $1.08,689$ participants, 2 trials, moderate-quality evidence) or reconsultation ( $\mathrm{RR} 1.08,95 \% \mathrm{Cl} 0.93$ to 1.27, 5132 participants, 4 trials, moderate-quality evidence). Procalcitonin-guided management probably results in little or no difference in treatment failure in general practice compared to normal care (adjusted OR 0.95, 95\% Cl 0.73 to 1.24, 1008 participants, 2 trials, moderatequality evidence), however it probably reduces treatment failure in the emergency department compared to usual care (adjusted OR 0.76 , $95 \% \mathrm{Cl} 0.61$ to $0.95,2605$ participants, 7 trials, moderate-quality evidence).

The quality of evidence for interventions focused on clinician educational materials and decision support in reducing antibiotic prescribing in general practice was either low or very low (no pooled result reported) and trial results were highly heterogeneous, therefore we were unable draw conclusions about the effects of these interventions. The use of rapid viral diagnostics in emergency departments may have little or no effect on antibiotic prescribing (RR $0.86,95 \% \mathrm{Cl} 0.61$ to 1.22, 891 participants, 3 trials, low-quality evidence) and may result in little to no difference in reconsultation (RR $0.86,95 \% \mathrm{Cl} 0.59$ to $1.25,200$ participants, 1 trial, low-quality evidence).

None of the trials in the included reviews reported on management costs for the treatment of an ARI or any associated complications.

\section{Authors' conclusions}

We found evidence that CRP testing, shared decision making, and procalcitonin-guided management reduce antibiotic prescribing for patients with ARIs in primary care. These interventions may therefore reduce overall antibiotic consumption and consequently antibiotic resistance. There do not appear to be negative effects of these interventions on the outcomes of patient satisfaction and reconsultation, although there was limited measurement of these outcomes in the trials. This should be rectified in future trials.

We could gather no information about the costs of management, and this along with the paucity of measurements meant that it was difficult to weigh the benefits and costs of implementing these interventions in practice.

Most of this research was undertaken in high-income countries, and it may not generalise to other settings. The quality of evidence for the interventions of educational materials and tools for patients and clinicians was either low or very low, which prevented us from drawing any conclusions. High-quality trials are needed to further investigate these interventions.

\section{PLAIN LANGUAGE SUMMARY}

\section{Strategies to help doctors change the way they prescribe antibiotics for patients with acute respiratory infections}

\section{Overview question}

This overview aimed to summarise all evidence from systematic reviews on strategies directed at doctors to reduce the antibiotic prescriptions they give to patients with acute respiratory infections (ear, nose, throat or chest infections).

\section{Background}

It is important that antibiotics are used for illnesses where they can make a difference to patients' symptoms and recovery and that they are available for those infections that are serious and can lead to disability or death. Antibiotics may make very little or no difference for patients who have ear, nose, throat, or chest infections that are caused by a virus (e.g. a cold, flu, or sore throat). Doctors can prescribe antibiotics too readily for patients with these symptoms. Strategies to change doctors' antibiotic prescribing habits have been developed to reduce the number of antibiotics given to patients with these symptoms. Several types of strategies exist, and it is important to bring together all the information on how these work.

\section{Study characteristics}

We identified five Cochrane Reviews and three non-Cochrane reviews. The reviews varied in how many trials they included and the number of participants within trials. The quality of both the reviews and trials varied. 


\section{Key results}

We found moderate-quality evidence that three types of strategies probably help to reduce antibiotic prescribing in primary care. Strategies that encourage the use of shared decision making between doctors and their patients, C-reactive protein tests, and procalcitonin-guided management (both tests that measure the amount of proteins in the blood, which may be raised in the case of infection) all probably reduce antibiotic prescribing in general practice. Procalcitonin-guided management also probably reduces antibiotic prescribing in emergency departments. These strategies seem to change antibiotic prescribing whilst keeping patients happy with their consultation and ensuring that they did not need to return to their doctor for the same illness. There was no information about the cost of these strategies, so it was difficult to weigh up the benefits and costs.

The quality of the evidence for strategies that aim to educate doctors about antibiotic prescribing, that provide decision aids for doctors to help them change their prescribing, and for the use of rapid viral diagnostics in emergency departments was either low or very low, meaning that we were unable to draw firm conclusions about the effects of these strategies.

In conclusion, we determined that some strategies aimed at doctors can probably help to reduce antibiotic prescribing in primary care. Further studies are needed for other types of strategies where there is less information about whether they can change prescribing. 


\section{B A C K G R O U N D}

\section{Description of the condition}

Antibiotic resistance is a major threat to human health worldwide (WHO 2015). Two million people are directly affected by antibioticresistant infections, of whom 23,000 die, annually in the USA (CDC 2013), with similar numbers in Europe (Lancet 2009). Infections caused by drug-resistant bacteria put patients at increased risk of worse clinical outcomes and death, and consume more healthcare resources (WHO 2015). The economic cost has been estimated at USD 55 billion per year in the USA, although the real cost may be much higher (Smith 2013). Unless addressed, this situation will worsen, with 10 million deaths estimated globally every year by 2050, and economic costs of USD 100 trillion from a reduction in overall economic production (O'Neill 2014).

Antibiotic resistance is an inevitable consequence of antibiotic use because antibiotics kill only bacteria that are sensitive and not pre-existing antibiotic-resistant bacteria (Spellberg 2013). Globally, human consumption of antibiotics increased by $36 \%$ between 2000 and 2010 (Van Boeckel 2014). This is reflected in European increases in antibiotic prescriptions (Adriaenssens 2011). In the UK, 949.9 tonnes of antibiotics were used in 2013 , with $56 \%$ being for human, rather than animal, use (PHE 2013). In Australia, $47 \%$ of the population are prescribed at least one antibiotic every year (ACSQHC 2016). For the individual patient, recent antibiotic use is the single most important risk factor for antibiotic-resistant infection (Chung 2007; Malhotra-Kumar 2007), with longer and multiple courses of antibiotics associated with even higher rates of resistance (Costelloe 2010). No new classes of antibiotics have been developed in the last two decades, and urgent investment in the discovery and development of new antimicrobial drugs has been proposed (Huttner 2013; O'Neill 2014).

However, resistance is reversible: in individuals, stopping the use of antibiotics results in the exponential decay of resistance in the bacteria of their microbiome (Costelloe 2010). This supports the case for strategies that promote more prudent use of antibiotics (O'Neill 2014). There are various approaches to this, including: promotion of narrow- over broad-spectrum antibiotics; prescribing the shortest clinically effective course; and achieving a total reduction in antibiotics prescribed.

Most antibiotics are prescribed in primary care, and most commonly for acute respiratory infections (ARIs) (Goossens 2005; Gulliford 2014; Shapiro 2014). Antibiotics are highly effective for some ARIs (including community-acquired bacterial pneumonia and acute exacerbation of chronic obstructive pulmonary disease (COPD)). However, the vast majority of ARIs are seen in primary care and in most cases are spontaneously resolved without antibiotics. These ARIs derive only marginal clinical benefits from antibiotics, which have to be balanced against the increased risks of harms associated with mild adverse events, and antibiotic resistance. Treated with antibiotics, one-third fewer children with acute otitis media had pain at days 2 to 3 (number needed to treat for an additional beneficial outcome $($ NNTB $)=20)$ (Venekamp 2015), and the duration of sore throat and acute bronchitis (cough) was reduced by 12 to 16 hours (NNTB to prevent one sore throat = 21) (Smith 2014; Spinks 2013). Meanwhile, the risk of vomiting, diarrhoea, or rash increased (number needed to treat for an additional harmful outcome (NNTH) $=9$ for acute otitis media, and NNTH $=24$ for acute bronchitis).
The management of ARIs in primary care is therefore a key target for influencing the antibiotic prescribing behaviour of clinicians. This is most often done by encouraging reduced prescribing of antibiotics for ARI. The use of delayed prescriptions by clinicians can also change both clinician and patient behaviour by changing the type of prescription written and decreasing the likelihood that an antibiotic prescription is used.

\section{Description of the interventions}

Many interventions that target clinicians also frequently target patients or the public, acknowledging the influence of patient expectations and concerns on prescribing. However, in many countries an antibiotic cannot be prescribed without the prescribing clinician's consent. In addition, the type of prescription written, whether it is for immediate or delayed use, is also the clinician's decision and should be considered as an additional, distinct type of prescribing behaviour. This overview focussed on two prescribing behaviours, that is whether an antibiotic is:

1. prescribed;

2. prescribed for immediate or delayed use.

We focussed on interventions aimed at influencing primary care clinicians' antibiotic prescribing behaviour for patients with ARIs. We have included all ARIs, acknowledging that antibiotic prescribing for some conditions (such as bacterial pneumonia and mastoiditis) is entirely appropriate for all cases, while for others (such as acute otitis media, sore throat, acute bronchitis, and acute sinusitis) antibiotic prescribing may be useful for only a proportion. The interventions could have included:

1. educational materials for clinicians: printed, electronic, or audio-visual materials that target the healthcare professional;

2. educational meetings: healthcare professionals attending conferences, lectures, training courses, or workshops;

3. educational outreach visits: healthcare professionals receiving information from a trained professional in their practice setting;

4. audit and feedback: any summary of clinical performance of health care over a specified time period provided to the healthcare professional;

5. reminders: verbal, written, or electronic information intended to prompt a healthcare professional to recall information, to include (computer) decision support systems;

6. financial interventions: targeting the healthcare professional to include financial incentives (e.g. fee-for-service) and financial penalties (e.g. direct or indirect financial penalty for inappropriate behaviour);

7. point-of-care tests (POCTs): equipment for use by healthcare professionals in their practice setting, to be used at the time and place of patient care, to provide rapid diagnostic information to help reduce the uncertainty associated with clinical diagnosis;

8. communication strategies: any resource targeted at the healthcare professional that encourages discussion with a patient about management options including:

a. clinician-delivered patient educational interventions;

b. improved communication interventions (for clinician-patient interaction);

c. shared decision making (as defined by Coxeter 2015, i.e. the process of enabling a health professional and patient to 
make a joint decision about management based on the best available evidence and the patient's values and preferences);

9. mass media campaigns: targeted at the healthcare professional at the population level employing varied use of communication;

10.delayed prescription strategy: any resource targeted at the healthcare professional that encourages giving a prescription for a patient to collect or use later than the initial consultation if symptoms do not improve;

11.any other intervention targeted at the clinician and aimed at changing antibiotic prescribing behaviour.

\section{How the intervention might work}

Strategies targeting clinician behaviour are complex interventions, meaning there is no single proposed mechanism of action. Multiple factors influence clinician antibiotic prescribing behaviour: knowledge of guidelines, previous clinical experience, diagnostic uncertainty, workload, and perceived patient expectations for antibiotics (Tonkin-Crine 2011).

Interventions may provide education (including professional continuing education, provision of guidelines, decision support, educational outreach visits, audit and feedback, and patient information leaflets) to fill knowledge gaps and misperceptions. Interventions may seek to tackle diagnostic uncertainty by providing more information to the clinician and thus increasing self efficacy in managing the patient (e.g. through use of POCTs). Interventions may also seek to encourage enhanced communication between clinician and patient to discuss the benefits and harms of antibiotic treatment, thus decreasing concerns about negatively affecting patient satisfaction (e.g. shared decision making, enhanced communication skills training). Different combinations of these might be expected to achieve a greater effect if they operate through different mechanisms (Arnold 2005).

Much of the research undertaken hitherto has examined the effect of interventions, with less emphasis on process evaluation, which examines how interventions work (or do not work) (Moore 2015). Where process evaluations have been carried out, interventions that support general practitioners to use C-reactive protein (CRP) POCTs or communication skills training, or both, appear to be effective because they increased the perceived importance of reducing antibiotic prescribing and decreased concerns regarding the safety of reducing antibiotic prescribing (Yardley 2013).

\section{Why it is important to do this overview}

Antibiotic prescribing is a major driver for the development of antibiotic-resistant infections. Antibiotics are commonly prescribed in the management of ARIs in primary care, despite good evidence that they are only weakly effective in the vast majority.

There are many interventions aimed at influencing antibiotic prescribing for ARIs. However, the multiple systematic reviews evaluating their effectiveness have not been synthesised. This overview aimed to synthesise evidence from systematic reviews (rather than individual trials) and assess the effectiveness of these interventions to enable policymakers as well as clinicians to design processes for future management of antibiotic resistance in primary care, and researchers to focus on any gaps in the current evidence.

\section{O B JECTIVES}

To systematically review the existing evidence from systematic reviews on the effects of interventions aimed at influencing clinician antibiotic prescribing behaviour for ARIs in primary care.

\section{METHODS}

\section{Criteria for considering reviews for inclusion}

\section{Types of reviews}

We included all published systematic reviews (Cochrane and non-Cochrane) of randomised controlled trials (RCTs) (including parallel-group, cluster, and factorial) testing interventions aimed at changing antibiotic prescribing in primary care for ARIs. We included reviews that included primary studies of non-RCT designs, but only where RCT data were reported separately, where individual study data could be obtained. As stated in our protocol, we excluded reviews when there was complete overlap with an existing included review (overview authors decided which review to include, with Cochrane Reviews given priority over non-Cochrane reviews, as they reported more detail) and where reviews were rated as having a high risk of bias.

\section{Types of participants}

We included reviews that studied interventions targeted at the antibiotic prescribing behaviour of clinicians for the treatment of ARIs in primary care. We included all ARIs, acknowledging that antibiotic prescribing for some conditions (such as bacterial pneumonia and mastoiditis) is entirely appropriate for all cases, while for others (such as acute otitis media, sore throat, acute bronchitis, and acute sinusitis) antibiotics prescribing may be useful for only a proportion of patients. Clinicians included anyone qualified to prescribe antibiotics. We included reviews that included trials from a variety of primary and ambulatory care settings. We also included reviews with trials that recruited participants from hospital inpatient settings, as well as primary or ambulatory care settings, providing data from the latter were reported separately. We defined primary care as any point-ofcare in which patients are managed at the first point of patient contact, and included general practice, out-of-hours services, and emergency departments. We excluded reviews solely in hospital inpatient settings and residential settings such as nursing homes, as these were not classed as primary care settings. Patients could be any age, presenting with an ARI, which was defined as any sudden-onset respiratory tract infection.

\section{Types of interventions}

We included any intervention designed to change the antibiotic prescribing behaviour of healthcare professionals for the management of ARIs in primary care. We included the following interventions: educational materials for clinicians, educational meetings, educational outreach visits, audit and feedback, reminders, financial interventions, point-of-care tests, communication strategies, mass media campaigns, delayed prescribing, or any other relevant intervention. Interventions could target healthcare professionals as a single population or as one of several groups. Interventions could be compared to usual care or an alternative intervention. 


\section{Types of outcome measures}

\section{Primary outcomes}

1. Change in antibiotic prescriptions for ARI (total number prescribed or proportion of patients prescribed antibiotics, to include a delayed prescription, measured as absolute change or relative percentage change).

\section{Secondary outcomes}

1. Prescribing outcomes:

a. proportion of patients with an ARI given an antibiotic prescription for immediate use;

b. proportion of patients with an ARI given a delayed antibiotic prescription.

2. Patient outcomes:

a. proportion of patients with an ARI colonised or infected with antibiotic-resistant bacteria;

b. adverse events;

c. symptom duration or severity;

d. health-related quality of life;

e. patient satisfaction;

f. any measure of management failure, e.g. reconsultation for the same illness, hospital or emergency department attendance.

3. Healthcare resource costs:

a. management costs for any medication for the treatment of an ARI or associated complications.

\section{Search methods for identification of reviews}

\section{Electronic searches}

We searched the Cochrane Database of Systematic Reviews (CDSR) and the Database of Abstracts of Reviews of Effects (DARE). We searched five additional databases in order to identify any other relevant systematic reviews. We incorporated search terms to target antibiotics, primary care settings, and ARIs but did not include intervention-specific search terms. Information Specialist Nia Roberts developed search strategies for all databases, which are presented in Appendix 1. We applied no language restrictions to the searches. We searched the following databases:

- Cochrane Database of Systematic Reviews (Issue 6 of 12, June 2016) and the Database of Abstracts of Reviews of Effects (Issue 2 of 4, April 2015) in the Cochrane Library (searched 9 June 2016);

- Epub Ahead of Print, In-Process \& Other Non-Indexed Citations, Ovid MEDLINE(R) Daily and Ovid MEDLINE(R) (1946 to 9 June 2016);

- Embase OvidSP (1974 to 9 June 2016);

- CINAHL (Cumulative Index to Nursing and Allied Health Literature) EBSCO (1982 to 9 June 2016);

- PsyciNFO (from 1967 to June Week 2 2016);

- Science Citation Index (Web of Science Core Collection) (1945 to 9 June 2016).

We also ran a pre-publication, updated search on 19 May 2017, screened the results, and placed relevant studies in 'Characteristics of studies awaiting classification' in Appendix 2. We will incorporate these in the next version of this review as appropriate.

\section{Searching other resources}

In addition to database searches, two overview authors (STC and $\mathrm{OvH}$ ) searched the reference lists of all included reviews.

\section{Data collection and analysis}

\section{Selection of reviews}

Two overview authors (STC and OvH) independently assessed the titles and abstracts of reviews identified by the search strategy. We excluded studies that were clearly not relevant. Both overview authors independently screened the full texts of potentially eligible reviews by applying the selection criteria. We agreed upon inclusion of reviews by consensus and, if necessary, by discussion with a third overview author (AMCC).

\section{Data extraction and management}

Two overview authors (STC and PST) independently extracted data from the full texts using a standardised data extraction form. The form included the following information:

1. general information (citation, author details, review ID);

2. aims and rationale;

3. extent of search (databases searched, restrictions);

4. eligibility criteria (types of studies included, whether RCTs reported separately);

5. participants within reviews (number of patients, age, primary care setting, indication for treatment);

6. interventions (type, target population);

7. comparator(s);

8. outcomes assessed; and

9. conclusions, recommendations, and limitations of the review.

We extracted data on details of the intervention(s) and comparison, effect of the intervention relative to control, number of trials and participants (patients), and quality of the evidence (using the Cochrane Handbook for Systematic Reviews of Interventions) (Higgins 2011).

We resolved discrepancies by consensus or by discussion with a third overview author (MPH). Where individual trials appeared in more than one included review, we noted the overlap and considered how trials had been interpreted by the author of each review. Where there was complete overlap in trials included within two or more reviews, two overview authors (STC and PST) discussed which review should contribute to the overview, based on the outcomes reported and risk of bias (Table 1).

\section{Assessment of methodological quality of included reviews}

\section{Quality of included reviews}

Two overview authors (STC and PST) independently assessed the methodological quality of each review using the ROBIS tool (Whiting 2016). ROBIS is an up-to-date tool that provides a thorough way of assessing risk of bias in reviews with a comprehensive set of items on which to judge reviews. The ROBIS tool has three phases, as follows.

\section{Phase 1: Assessing relevance (optional)}

This was not required, as the reviews had already been assessed for relevance to the research question. 


\section{Phase 2: Identifying concerns with the review process}

This consists of four domains against which a review is assessed:

1. study eligibility criteria;

2. identification and selection of studies;

3. data collection; and

4. study appraisal and synthesis and findings.

Each domain has five or six questions that are answered as 'Yes', 'Probably Yes', 'Probably No', 'No', and 'No Information'. We rated domains as 'Low Risk' if all questions were 'Yes' or 'Probably Yes'; 'High Risk' if they were 'No' or 'Probably No'; and judged the remainder as 'Unclear' (Whiting 2016).

\section{Phase 3: Judging risk of bias}

This summarises the concerns identified in Phase 2 and assesses whether conclusions are supported by evidence by considering three points:

1. interpretation of findings addresses all concerns identified in Phase 2;

2. relevance of identified studies to the research question is considered;

3. avoids emphasising results on basis of statistical significance.

We excluded reviews that were assessed as being at high risk of bias based on Phase 2 and Phase 3 of the ROBIS assessment Some reviews scored high risk on only a few items. We considered whether this influenced the overall result, and included reviews where high risk of bias due to omissions in original review reporting could be addressed in the overview.

We resolved differences in each overview author's assessment of quality by discussion. If we were unable to reach agreement, we recorded this, and a third overview author (MPH) adjudicated.

\section{Quality of evidence in included reviews}

\section{Risk of bias of individual trials}

The review authors reported risk of bias of trials in reviews. The overview authors extracted and summarised the data.

\section{GRADE assessments for each comparison/outcome}

Two overview authors (STC and PST) examined the included reviews for information on the quality of the trials within each review, and where described, extracted it for each outcome. Where this information was not provided, we used the GRADE tool to make a retrospective assessment (Guyatt 2008; Higgins 2011). We used the five GRADE considerations (study limitations, consistency of effect, imprecision, indirectness, and publication bias) to assess the quality of evidence of the trials contributing data for each outcome.

\section{Data synthesis}

We produced a narrative summary of all the results reported in the included systematic reviews and presented a summary of data using an 'Overview of reviews' table, which provides details of reviews based on all relevant outcomes.

We planned to perform subgroup analysis using Review Manager 5 software, data permitting, for the following (RevMan 2014);

1. adults (aged $\geq 18$ years) versus children;

2. placebo versus no intervention; and

3. combined interventions versus single intervention.

Data were not available to undertake the planned subgroup analysis or sensitivity analysis.

\section{RES U LTS}

We searched the databases in June 2016. Figure 1 shows the reviews identified at each stage of the search process. Our database searches identified 910 records, of which 314 were duplicates. We identified four additional papers from searching the references of included reviews. Of the 600 records, we excluded 577 after screening titles and abstracts. We assessed the full texts of the remaining 23 reviews, and excluded another 12 . This left 11 reviews for potential inclusion. We excluded an additional three reviews following the ROBIS assessment (Table 2; Appendix 3). 
Figure 1. Study flow diagram.

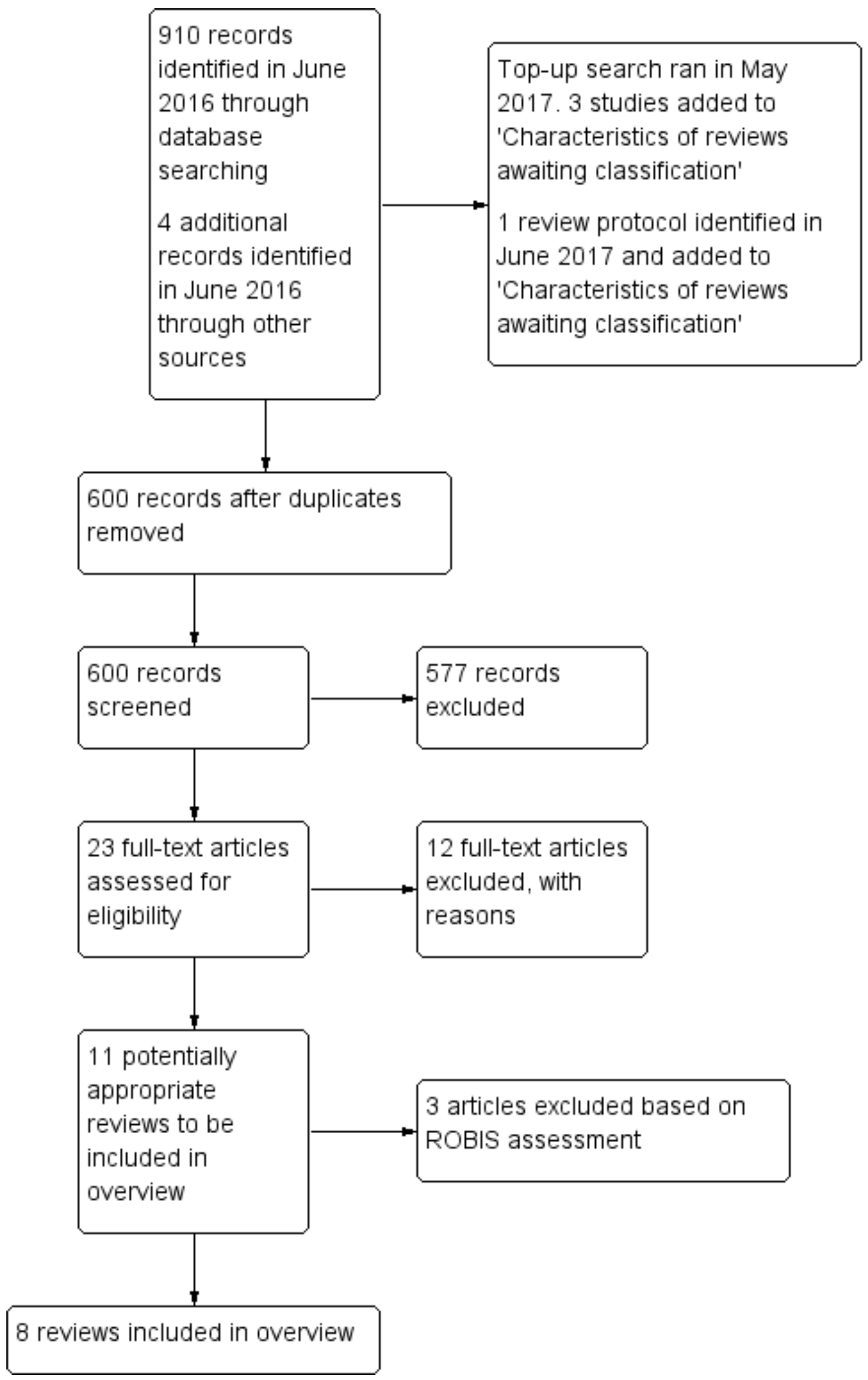

Clinician-targeted interventions to influence antibiotic prescribing behaviour for acute respiratory infections in primary care: an 
We re-ran the search in May 2017, identifying a total of 96 new references. We selected a further three reviews for in-depth assessment (Hu 2016; McDonagh 2016; O'Sullivan 2016). We also identified a systematic review protocol published in June 2017 that would likely meet our inclusion criteria once completed (MartinezGonzalez 2017). We added these four potential new reviews of interest to a list of 'Characteristics of studies awaiting classification', and we will incorporate them into overview findings during the next update (Appendix 2).

\section{Description of included reviews}

A summary of the included reviews can be found in Table 3. A list of reviews, interventions, and trials that contributed to the overview is presented in Table 1.

Two reviews focussed specifically on interventions used in emergency departments, whilst the remainder focussed on general practice or family practice depending on the countries included. Nearly all trials were undertaken in high-income countries, in particular Europe and North America, with the remainder in China. Both trials from China focussed on the use of procalcitonin-guided therapy in the emergency department. Most reviews and their included trials were conducted in the last 10 years; the oldest review was dated 2005, and the oldest trial 1995 . The majority of trials were carried out between 2003 and 2010.

Some trials were reported in more than one review (Table 1). Trials by Cals and colleagues, Cals 2009, Cals 2010, Cals 2013, appeared in two or more reviews (Aabenhus 2014; Coxeter 2015; Huang 2013). Little 2013 also appeared in Aabenhus 2014 and Coxeter 2015. Cals 2009 and Little 2013 both tested the effectiveness of two types of intervention on antibiotic prescribing: CRP testing and communication skills training for the clinician. As such, results about the effectiveness of different trial arms appear in reviews on CRP and on shared decision making. Due to the overlap in trials between Aabenhus 2014 and Huang 2013, only the three additional trials reported in Huang 2013 are discussed in addition to the results of Aabenhus 2014. The trial by Francis 2009 appears both in de Bont 2015 and Coxeter 2015, which consider the use of patient information leaflets by clinicians and shared decision making. The interactive aspect of the intervention by Francis 2009 is discussed, and its novelty in comparison to other patient information leaflets which are not used interactively is noted.

\section{Point-of-care tests}

Four of the eight included reviews assessed the use of a POCT as an intervention to change clinician antibiotic prescribing. Two assessed CRP testing, most often used as a near patient test which provided a result within minutes. One assessed rapid viral diagnostic testing in the emergency department (ED), where results were available during a patient's stay in the ED (within hours). Another assessed procalcitonin-guided management, where results were also available within hours.

Aabenhus 2014 searched six databases up to January 2014 and included six trials, all of which tested the effectiveness of CRP point-of-care testing on antibiotic prescribing for ARIs. The trials included 3284 participants; five trials included only adults (older than 17 years), and one trial included both adults and children (Diederichsen 2000). All trials were carried out in European general practice. The trials included three RCTs and three cluster-RCTs.
Huang 2013 searched two databases and included 13 studies, seven RCTs and six observational studies, to explore the effectiveness of CRP testing in the management of respiratory tract infections (RTIs) in general practice. We extracted only data from randomised trials for this overview: four were RCTs and three were cluster-RCTs. All trials were carried out in European general practice, except for one carried out in the USA (Gonzales 2011). The trials included a total of 2570 participants; six of the trials included adults only, and one included both adults and children (Diederichsen 2000).

Four trials assessed CRP testing and were identified by both Aabenhus 2014 and Huang 2013.

Four trials, of which three were RCTs (one quasi-RCT was not included), assessed rapid viral diagnostics in the management of children (aged less than 18 years) with ARI in the emergency department: Bonner 2003 recruited patients aged 2 to 21 years who presented to an ED in the USA with fever and ARI $(n=391)$; Poehling 2006 recruited patients age less than 5 years presenting with RTI in a US ED ( $~ 20 \%$ of patients were at high risk from asthma; $5 \%$ had a pre-diagnosis that required exclusion from the analysis $(n=300)$ ); Doan 2009 recruited patients aged 3 to 36 months presenting in an ED in Canada with febrile ARI $(n=200)$.

Schuetz 2012 searched three databases up to May 2011 and included 14 RCTs assessing procalcitonin in EDs, hospital wards, and intensive care units. We extracted data for nine of the 14 trials undertaken in outpatient settings, and included 3613 adult patients aged $\geq 18$ years. Two trials were undertaken with patients with ARI in general practice in Switzerland and Germany (Briel 2008; Burkhardt 2010); the remaining seven took place in the ED. Of the seven which took place in the ED, four trials were conducted in Switzerland (Christ-Crain 2004; Christ-Crain 2006; Schuetz 2009; Stolz 2007), two in China (Long 2009; Long 2011), and one in Denmark (Kristoffersen 2009). Three included participants with lower respiratory tract infections (LRTIS) (some studies with X-ray confirmation) (Christ-Crain 2004; Kristoffersen 2009; Schuetz 2009); three included participants with communityacquired pneumonia (CAP), with some participants undergoing $X$ ray confirmation (Christ-Crain 2006; Long 2009; Long 2011); and one included participants with COPD exacerbation (Stolz 2007).

Doan 2014 and Schuetz 2012 both included trials that recruited patients with chronic and more serious ARIs or complications (CAP, asthma, and COPD). However, we assumed that these trials focussed on ARIs because their aim was to reduce antibiotic prescribing, therefore we included them in this overview.

\section{Communication strategies}

\section{Shared decision making}

Coxeter 2015 searched four databases up to December 2014 and included 10 reports of nine original RCTs. All trials explored the effect of interventions that aim to facilitate shared decision making (SDM) on antibiotic prescribing for ARIs in primary care. Interventions were included if they explicitly stated that they incorporated SDM, or if the intervention included one of the elements of SDM described by Makoul 2006. The trials included a total of 490,083 participants; all trials were carried out in European general practice, except for two trials conducted in Canada (Légaré 2011; Légaré 2012); all trials were cluster-RCTs with the unit of randomisation as the individual general practitioner or practice group; four trials included patients of any age, while four included 
only adults, and one only children. Trials included patients with ARI, LRTI (and upper respiratory tract infection (URTI)), and acute cough.

\section{Patient information leaflets used by clinicians in consultations}

de Bont 2015 searched two databases up to April 2014 and included eight studies (seven RCTs, one non-RCT) assessing the effect of patient information leaflets on antibiotic use and reconsultation; two trials undertaken in UK general practice were relevant because they measured clinician antibiotic prescribing: Francis 2009 tested the effectiveness of an interactive patient booklet on management of children with acute RTI ( $n=558$ ); Macfarlane 1997 tested the effectiveness of a patient information leaflet on management of adults (aged more than 15 years) with acute LRTI $(n=1014)$.

\section{Educational materials for clinician and reminders}

Boonacker 2010 searched three databases up to February 2009 and included 10 studies, all of which assessed interventions to promote evidence-based practice for the management of children with URTI, which we regarded as largely synonymous with ARIs. The review included RCTs, non-RCTs, and controlled before-and-after studies. Two RCTs were relevant to this overview: Christakis 2001 assessed a computerised decision support system on clinicians' management of acute otitis media in a paediatric practice in the USA; Wilson 2002 studied the effect of collaborative development of guidelines and educational materials on clinicians' management of children aged less than 2 years with ARI in general practice in Australia. In both trials the intervention was targeted at individual clinicians, and patient numbers were not reported.

\section{Multifaceted interventions (multiple interventions used within one approach)}

Arnold 2005 searched three databases up to May 2000 and December 2002 and included 39 studies assessing professional interventions, as defined by the Cochrane Effective Practice and Organisation of Care Group (EPOC), to improve the selection, dose, and duration of antibiotics prescribed in the outpatient setting. The review included RCTs, non-RCTs, interrupted time series analysis, and controlled before-and-after studies. Five RCTs were relevant to this overview: three included only children (Finkelstein 2001; Flottorp 2002; Mainous 2000), and two included patients aged more than 15 years or aged more than 3 years (Mclsaac 1998; Mclsaac 2002). Two trials were undertaken in primary care settings in the USA (Finkelstein 2001; Mainous 2000), two in family practice in Canada (Mclsaac 1998; Mclsaac 2002), and one in general practice in Norway (Flottorp 2002). Both Canadian trials included interventions with printed educational materials for the clinician and reminders (Mclsaac 1998; Mclsaac 2002). Mainous 2000 included patient educational materials and audit and feedback for the clinician. Flottorp 2002 included clinician educational materials, reminders, patient education materials, computer decision support, and opportunities to gain continued professional development credit, and increased the price of telephone consultations. Finkelstein 2001 included clinician educational materials, audit and feedback, patient educational materials, and input from local opinion leaders. The number of patients seen within trials was not reported.

\section{Methodological quality of included reviews}

\section{Quality of included reviews}

Three reviews (all Cochrane Reviews) scored low risk across all of the ROBIS domains in Phase 2 and low risk of bias overall (Aabenhus 2014; Doan 2014; Schuetz 2012). The remaining five reviews scored high risk on Domain 4 of Phase 2, specifically on point 4.6 (whether biases in primary studies were minimal or addressed in the synthesis, because the 'Risk of bias' assessment had not been specifically considered and discussed in the review Results and Conclusions) (Table 1) (Arnold 2005; Boonacker 2010; Coxeter 2015; de Bont 2015; Huang 2013).

\section{Quality of evidence in included reviews}

\section{Risk of bias of individual trials}

Review authors assessed the risk of bias of trials within reviews using the Cochrane 'Risk of bias' tool (Higgins 2011); the results are presented in Table 4. One review used EPOC criteria instead, which is available on the EPOC website as "suggested risk of bias criteria" (epoc.cochrane.org/epoc-specific-resources-reviewauthors) (Arnold 2005). This mostly replicated the Cochrane 'Risk of bias' tool, except that it did not assess random sequence generation, blinding of participants, or selective reporting of data.

Trials within reviews were generally scored as at low risk of bias on random sequence generation, incomplete outcome data, and selective reporting. Allocation concealment and blinding of outcome assessment were more often judged to be at unclear or high risk of bias, and blinding of participants was infrequently reported due to the nature of the interventions being delivered, and was thus judged as at high risk of bias. Review authors did not often report risk of other bias, or they reported that information from individual trials was unclear. Aabenhus 2014 and Huang 2013 included four trials that appeared in both reviews. However, the 'Risk of bias' assessment reported in each review was distinctly different for random sequence generation and blinding of outcome assessment. Additional information about 'Risk of bias' assessment in Huang 2013 was not available. However, Aabenhus 2014 (a Cochrane Review) provided more detail and assessed the risk of bias for each trial.

\section{GRADE assessments for each comparison/outcome}

Only three included reviews (all Cochrane Reviews) used GRADE criteria to summarise the quality of evidence for each of their outcomes (Table 5) (Aabenhus 2014; Coxeter 2015; Schuetz 2012). Aabenhus 2014 reported that evidence for the effect of CRP testing on four outcomes was of moderate quality as assessed by the GRADE criteria. Evidence was downgraded primarily based on imprecision of the estimated effect. Coxeter 2015 and Schuetz 2012 reported that the evidence for the effect of shared decisionmaking interventions and procalcitonin-guided management on antibiotic prescribing was also of moderate quality. Evidence was downgraded primarily due to high risk of bias in included trials.

We used GRADE to summarise the quality of the evidence for each type of intervention and each primary outcome for the remaining reviews (Table 5) (Guyatt 2008; Higgins 2011). We assessed the quality of evidence for outcomes reported by Doan 2014 as low, downgrading because of high risk of bias in included trials due to lack of allocation concealment and lack of blinding of participants, and due to imprecision as a result of wide confidence intervals. We 
assessed three of the trials reported in Huang 2013 individually due to overlap with Aabenhus 2014. We assessed two trials, undertaken in general practice, to be of moderate quality, downgrading because of high risk of bias due to inadequate methods of sequence generation, lack of allocation concealment, and lack of blinding of participants. We downgraded the third trial, carried out in the $E D$, because of high risk of bias and imprecision as a result of wide confidence intervals and small sample size. We assessed the quality of evidence for outcomes reported by Boonacker 2010 as very low, downgrading because of high risk of bias in included trials, reported publication bias, and imprecision due to sample size not being reported. We assessed the quality of evidence for outcomes reported by de Bont 2015 and Arnold 2005 as low or very low, downgrading because of high risk of bias in included trials, inconsistency in results, and imprecision due to wide confidence intervals and sample size not being reported (Table 5).

\section{Effect of interventions}

A summary of results is presented in Table 5.

Subgroup analyses were not possible due to the heterogeneity of included reviews and the data available.

\section{Change in antibiotic prescriptions for ARI}

\section{Point-of-care tests}

\section{CRP testing}

Aabenhus 2014 and Huang 2013 both presented moderate-quality evidence that CRP testing probably reduces antibiotic prescribing in general practice compared to usual care.

Aabenhus 2014 found an overall effect of CRP testing showing that antibiotic prescribing is probably decreased at the initial consultation: risk ratio (RR) $0.78,95 \%$ confidence interval $(\mathrm{CI}) 0.66$ to $0.92,3284$ participants, 6 trials, moderate-quality evidence). Aabenhus 2014 reported that the effect of CRP testing on prescribing is probably maintained at 28 days postconsultation, meaning that patients did not receive a prescription from the same practice at a later date (RR $0.80,95 \% \mathrm{Cl} 0.67$ to $0.96,3284$ participants, 6 trials, moderate-quality evidence).

Huang 2013 reported seven trials that investigated the effects of CRP testing in both general practice and EDs. We have reported the three trials that were not included in the review by Aabenhus 2014. Two trials in general practice showed that CRP testing probably led to a decrease in antibiotic prescriptions compared to usual care (Cals 2011 (RR $0.57,95 \% \mathrm{Cl} 0.44$ to $0.74 ; 330$ participants) and Cals 2013 (RR 0.58, 95\% Cl 0.45 to 0.74; 379 participants) (moderatequality evidence)).

Huang 2013 presented low-quality evidence from a single small trial showing that CRP testing may have little or no effect on antibiotic prescribing in EDs compared to usual care (RR 1.23, $95 \% \mathrm{Cl} 0.76$ to $1.99,131$ participants, 1 trial, low-quality evidence) (Gonzales 2011).

\section{Rapid viral diagnostics}

Doan 2014 found that rapid viral diagnostics may have little or no effect on antibiotic prescribing in the ED compared to usual care (RR $0.86,95 \% \mathrm{Cl} 0.61$ to $1.22,891$ participants, 3 trials, low-quality evidence).

\section{Procalcitonin-guided management}

Schuetz 2012 reported the effect of procalcitonin measurement on the initiation of antibiotics and found that it probably decreased antibiotic initiation in both general practice (adjusted odds ratio (OR) $0.10,95 \% \mathrm{Cl} 0.07$ to $0.14,1008$ participants, 2 trials, moderatequality evidence) and the ED (adjusted OR $0.34,95 \% \mathrm{Cl} 0.28$ to 0.43 , 2605 participants, 7 trials, moderate-quality evidence) compared to usual care.

\section{Shared decision making}

Coxeter 2015 reported moderate-quality evidence showing that shared decision making probably reduces antibiotic prescribing compared to usual care. They pooled the results of trials using three sets of adjusted effect estimates as part of a sensitivity analysis: set one (OR $0.44,95 \% \mathrm{Cl} 0.26$ to $0.75,3274$ participants, 3 trials); set two (recalculating the adjusted RR) (RR $0.64,95 \% \mathrm{Cl} 0.49$ to $0.84,4623$ participants, 2 trials); and set three (risk difference (RD) $-18.44,95 \% \mathrm{Cl}-27.24$ to $-9.65,481,807$ participants, 4 trials). This overview reports only these analyses from Coxeter 2015, which examined the effect of shared decision making on antibiotic prescribing by the clinician. Other analyses focussed on "antibiotics prescribed, dispense or decision to use" were not extracted as these included assessing the effect of shared decision making on patient behaviour.

\section{Patient information leaflets used by clinicians in consultations}

de Bont 2015 reported very low-quality evidence from two trials assessing the effectiveness of patient information leaflets on the antibiotic prescribing of general practitioners, one showing a subsequent reduction in prescribing (RR $0.47,95 \% \mathrm{Cl} 0.36$ to $0.64,558$ participants) (Francis 2009), and one showing no evidence of an effect (RR 1.15, 95\% Cl 0.89 to $1.48,1014$ participants) (Macfarlane 1997). We are therefore uncertain about whether patient information leaftlets reduce antibiotic prescribing compared to usual care.

\section{Educational materials for clinicians and reminders}

Boonacker 2010 reported very low-quality evidence from two trials on the effect of computerised decision support on antibiotic prescribing (Christakis 2001; Wilson 2002), therefore we are uncertain as to whether this has an effect compared to usual care. One of the included trials, Christakis 2001, presented evidence of an increase in antibiotic prescribing by both the intervention and control groups, but suggested that the intervention had a preventive effect by avoiding further increases in the rate of antibiotic prescribing (RD $-12 \%, \mathrm{Cl}$ not reported, $\mathrm{P}=0.095$, participant number not reported). The second included trial, Wilson 2002, reported evidence that collaborative development of guidelines and education materials resulted in a reduction in antibiotic prescribing for ARI episodes (adjusted OR $0.60,95 \% \mathrm{Cl}$ 0.43 to 0.83 , participant number not reported).

\section{Multifaceted interventions (multiple interventions used within one approach)}

Arnold 2005 reported five trials using multifaceted interventions (Finkelstein 2001; Flottorp 2002; Mainous 2000; Mclsaac 1998; Mclsaac 2002).

Mclsaac 1998 and Mclsaac 2002 reported very low-quality evidence on the effect of printed educational materials for clinicians with or 
without reminders compared to usual care, meaning that we are uncertain about their effects on antibiotic prescribing compared to usual care. One trial found reduced antibiotic prescribing (OR $0.44,95 \% \mathrm{Cl} 0.21$ to 0.92 , participant number not reported) (Mclsaac 1998), while the other showed no effect (OR $0.57,95 \% \mathrm{Cl} 0.27$ to 1.17, participant number not reported) (Mclsaac 2002).

Mainous 2000 reported low-quality evidence that audit and feedback alone or with patient education materials may reduce clinicians' antibiotic prescribing compared to usual care. They reported an increase in antibiotic prescribing for all groups, although groups that received patient education materials (with or without audit and feedback) prescribed significantly fewer antibiotics than the control $(T=2.374, P<0.05$ (exact $P$ value not given), participant number not reported).

Finkelstein 2001 presented low-quality evidence that educational materials and educational meetings for clinicians with patient education materials may reduce antibiotic prescribing compared to usual care in populations aged 3 to 36 months (16\%, $8 \%$ to $23 \%$ ) and 36 to 72 months (12\%, $2 \%$ to $21 \%$ ) (participant numbers not reported).

Flottorp 2002 also presented low-quality evidence that a multifaceted intervention containing five component interventions may slightly reduce antibiotic prescribing compared to usual care $(-3.0 \%$ compared with control, $\mathrm{P}=0.03$, participant number not reported). The intervention included education materials for the clinician, computerised decision support, professional development, financial incentives, and patient education materials.

\section{Proportion of patients with an ARI given an antibiotic prescription for immediate use and proportion of patients with an ARI given a delayed antibiotic prescription}

None of the trials in the included reviews reported the proportion of patients who were provided with antibiotic prescriptions for immediate or delayed use.

\section{Proportion of patients with an ARI colonised or infected with antibiotic-resistant bacteria}

None of the trials in the included reviews reported the proportion of patients colonised or infected with antibiotic-resistant bacteria.

\section{Adverse events}

Only two of the eight reviews reported on adverse events.

Aabenhus 2014 reported moderate-quality evidence that CRP point-of-care testing probably results in little or no difference in adverse events compared to usual care. One of the trials in this review, Little 2013, found evidence of increased hospitalisation in patients for the trial arm using the CRP test (crude RR 2.53, 95\% Cl 1.13 to 5.66), although after adjusting for the trial's cluster design, the difference was not significant (RR 2.45, 95\% Cl 0.65 to 9.19, 4264 participants, moderate-quality evidence). Aabenhus 2014 reported no deaths in any of the six trials evaluating CRP testing.

Coxeter 2015 reported that six of the nine trials evaluating shared decision making reported serious adverse events requiring hospitalisation, but the review authors reported that there was no difference between intervention and control groups. One trial reported a death due to myocardial infarction following pneumonia for an elderly patient in the control arm of the trial (Briel 2006). No trials reported on all-cause mortality.

\section{Symptom duration or severity}

Aabenhus 2014 was the only review to report on symptom duration or severity, from three trials evaluating CRP testing (either as a median symptom duration to full recovery, or resolution of symptoms rated moderately bad or worse) (Cals 2009; Cals 2010; Little 2013). The review authors presented moderate-quality evidence that CRP point-of-care testing probably results in little or no difference in symptom duration or severity compared to usual care at seven days (RR $1.03,95 \% \mathrm{Cl} 0.93$ to $1.14,1309$ participants, 3 trials) or at 28 days (RR $0.94,95 \% \mathrm{Cl} 0.69$ to 1.28 , 849 participants, 3 trials).

\section{Health-related quality of life}

Schuetz 2012 was the only review to report on health-related quality of life of participants taking part in a trial of procalcitonin on prescribing, finding moderate-quality evidence that procalcitoninguided management probably results in little or no difference in days of restricted activities after 14 days (adjusted difference in days $0.05,95 \% \mathrm{Cl}-0.46$ to $0.56, \mathrm{P}=0.854,1008$ participants, 2 trials, moderate-quality evidence).

\section{Patient satisfaction}

Three reviews reported on patient satisfaction. Aabenhus 2014 and Huang 2013 reported the same two trials evaluating CRP testing (Cals 2009; Cals 2010), finding moderate-quality evidence that CRP point-of-care testing probably results in little or no difference in patient satisfaction compared to usual care (RR $0.79,95 \% \mathrm{Cl} 0.57$ to $1.08,689$ participants, 2 trials, moderate-quality evidence). Coxeter 2015 reported patient satisfaction for two trials evaluating shared decision making, finding that shared decision making may result in little or no difference in patient satisfaction compared to usual care (RR $0.86,95 \% \mathrm{Cl} 0.57$ to $1.30,1110$ participants, 2 trials, low-quality evidence).

\section{Management failure}

This outcome was most often reported as reconsultation for the same illness episode. Aabenhus 2014 found CRP point-of-care testing probably results in little or no difference in reconsultation compared with usual care at 28 days' follow-up (RR 1.08, 95\% Cl 0.93 to $1.27,5132$ participants, 4 trials, moderate-quality evidence). Likewise, Coxeter 2015 found that shared decision making probably results in little or no difference in reconsultation for the same illness compared to usual care (RR $0.87,95 \% \mathrm{Cl} 0.74$ to $1.03,1860$ participants, 4 trials, moderate-quality evidence). de Bont 2015 reported very low-quality evidence from two trials that measured reconsultations for interventions with patient information leaflets. One trial showed evidence of a reduction in reconsultation in patients who had received the intervention ( $\mathrm{RR} 0.70,95 \% \mathrm{Cl} 0.53$ to $0.91,1014$ participants) (Macfarlane 1997); however, the second trial showed no evidence of an effect (RR $0.80,95 \% \mathrm{Cl} 0.52$ to 1.21 , 558 participants). We are therefore uncertain about the effect of patient intervention leaflets on reconsultation compared to usual care (Francis 2009). Doan 2014 reported low-quality evidence from one trial on the effect of rapid viral diagnosis on doctors' visits within two weeks of discharge following patients' visits to the ED. The review authors found that testing may have little to no effect 
on reconsultation compared to usual care ( $\mathrm{RR} 0.86,95 \% \mathrm{Cl} 0.59$ to 1.25, 200 participants, 1 trial, low-quality evidence) (Doan 2009).

Schuetz 2012 found moderate-quality evidence that procalcitoninguided management probably results in little or no difference in treatment failure in general practice compared to normal care (adjusted OR $0.95,95 \% \mathrm{Cl} 0.73$ to $1.24,1008$ participants, 2 trials, moderate-quality evidence). For patients seen in the $E D$, there was moderate-quality evidence that procalcitoninguided management probably reduces treatment failure in the ED compared to usual care (adjusted OR 0.76, 95\% Cl 0.61 to 0.95, 2605 participants, 7 trials, moderate-quality evidence).

\section{Management costs for any medication for the treatment of an ARI or associated complications}

None of the trials in the included reviews reported on management costs for the treatment of an ARI or any associated complications.

\section{DISCUSSION}

\section{Summary of main results}

This overview identified eight reviews assessing clinician-focussed interventions to influence antibiotic prescribing for ARIs in primary care. There was moderate-quality evidence indicating that pointof-care CRP testing (two reviews, nine trials), procalcitoninguided management (one review, nine trials), and shared decision making (one review, nine trials) probably safely reduce antibiotic prescribing in the management of ARIs compared to usual care.

The overall effect of these interventions was small (few achieving greater than $50 \%$ reduction in antibiotic prescribing, most about a quarter or less), but is likely to be clinically important. The interventions we have reported likely influence different mechanisms of behaviour change, so it is possible that combining interventions will result in greater effects.

For the other interventions, including multifaceted interventions, those centred on clinician education, patient information leaflets, and the use of rapid viral diagnostics, the evidence was of low or very low quality across outcomes, and we could not confidently draw any conclusions about the effects of these interventions compared to usual care. Further primary research is necessary to improve the evidence base in order to be able to make informed decisions about the value of these interventions.

None of the trials in the included reviews reported on management costs for the treatment of an ARI or any associated complications.

\section{Overall completeness and applicability of evidence}

The inclusion of both Cochrane and non-Cochrane reviews provides a comprehensive summary of all eligible systematic reviews. The reviews reported on a wide range of interventions, although for each intervention there were few reviews. Most reviews addressed the effects of diagnostic tests on antibiotic prescribing. One of the included reviews investigated multifaceted interventions containing multiple components, including clinician and patient education, audit and feedback, and reminders. Since no review studied these interventions alone, the separate effects of each are unknown. clinical practice. The use of CRP testing and shared decision making in general practice was explored frequently in trials and reviews, and there appears to be sufficient evidence for policymakers and clinicians to decide whether these interventions would be useful in their own contexts. However, sufficient detail for replication was lacking for the other intervention types under the categories of clinician education, patient information leaflets, and reminders. This was reflected in the original trials. Similarly, 'usual care' - the control arm of most trials - was also poorly described.

There is a risk that in categorising interventions in the way that we did for this overview, we inadvertently grouped those with different underlying mechanisms of behaviour change. For example, of the two trials of patient information leaflets, effectiveness was only demonstrated when the leaflet was used "interactively" as part of the intervention. Future investigators of trials and reviews should describe interventions more comprehensively. Other review authors have further considered and classified the different components of interventions categorised in this way (Davey 2017).

It is possible that a combination of intervention types would have an additive (or even multiplicative) effect because they probably act with quite separate mechanisms of action (notwithstanding the unknown nature of these). However, ideally these should be tested separately as well as in combination.

Few trials compared interventions against one another, so we had no data to assess the relative performance of different interventions.

Although our search identified reviews of delayed-prescribing interventions, none measured antibiotic prescribing behaviour as an outcome, which focusses on both clinicians (to change their behaviour to writing delayed, rather than immediate, prescriptions, and provide accompanying advice to patients) as well as patient behaviour (by giving them responsibility about whether or when they access antibiotics). The trials randomised patients to immediate, delayed, or no-prescription arms, and since consumption of antibiotics was the most common primary outcome, there was no measure of only the clinicians' behaviour.

Three of our prespecified outcomes were not reported in the contributing reviews. These outcomes were the proportion of patients receiving an antibiotic prescription for immediate or delayed use, the proportion of patients with an ARI colonised or infected with antibiotic-resistant bacteria, and the management cost of any medication to treat an ARI or any associated complications. Delayed prescriptions are often not easily identifiable in general practice records, as they most often reflect a change in the verbal instructions given to a patient rather than a change in the issuing of the prescription; as such, it is a difficult outcome for trials to measure. Similarly, identifying antibiotic-resistant bacteria requires lab samples, which adds complexity and cost to an RCT. The cost-effectiveness of interventions in this area is not commonly examined, and further research in this field is needed.

Most of the trials in the included reviews were undertaken in high-income countries, in particular countries in Europe and North America, and their findings may not be applicable in other settings.

The descriptions of point-of-care diagnostics and shared decision making interventions were detailed enough to enable replication in 


\section{Quality of the evidence}

The reviews included in this overview were conducted to a high standard, although five of the eight reviews were marked down on one ROBIS domain because potential biases in primary studies were not considered in the interpretation of findings or in the discussion. The three reviews that scored low risk on all four ROBIS domains were all Cochrane Reviews, although a further Cochrane Review was also marked down on domain 4 of ROBIS, as were the non-Cochrane reviews (Table 1 ).

The quality of evidence in included reviews was rated according to the GRADE criteria. The quality varied, with no outcomes rated as having high-quality evidence in any included review. The most common reason for downgrading quality of evidence for each outcome was when there was judged to be a high risk of bias in the relevant trials and/or when there was imprecision in the main effect. The unavoidable lack of blinding of participants increased the risk of bias in trials. However, blinding of outcome assessment and allocation concealment was also generally not reported, which increased the risk of bias, particularly for trials investigating the effect of POCTs used by clinicians.

For the reviews in which the quality of evidence for outcomes was rated as low, evidence was downgraded by one level when there was judged to be high risk of bias, and a second level due to inconsistency in results, imprecision, or reported publication bias. Where evidence was rated as very low, evidence was downgraded another level due to imprecision in the effect estimate. The GRADE ratings for each outcome in each review are presented in Table 5 , along with footnotes describing the rationale for each downgrading decision.

\section{Potential biases in the overview process}

Our methods of independent assessment of bias and data extraction (with arbitration by a third overview author) should have reduced the risk of bias in generating this overview. However, we could not formally assess the risk of publication bias in this overview because there were too few reviews, nor was this assessed in the included reviews. If studies that were narrative reviews (i.e. without quantification of the results) were more likely to be negative, our exclusion of them might have introduced publication bias.

Where reviews did not report quality of evidence according to GRADE criteria, we applied this retrospectively. This approach was limited as it used 'Risk of bias' assessments made by the review authors, and the depth of reporting between reviews varied. When reviews did report quality of evidence according to GRADE criteria, we reported the findings of the review authors.

Some overview authors are also authors on included reviews, which had the potential to introduce bias when presenting the results. However, the data extraction, narrative summary, and reporting of the overview was led by three overview authors who had no connection to previous reviews in order to minimise any bias.

\section{Agreements and disagreements with other studies or reviews}

We excluded many reviews because they did not meet our inclusion criteria. However, we are not aware of any other quantitative published overviews of reviews of clinician-targeted interventions to reduce antibiotic prescribing for acute ARIs.

\section{AUTHORS' CONCLUSIONS}

\section{Implications for practice}

We found insufficient evidence to identify which types of intervention or intervention components are most effective at influencing antibiotic prescribing behaviour for acute respiratory infection (ARI) in primary care. Moderate-quality evidence suggests that the following interventions likely have an important effect on reducing antibiotic prescribing:

- C-reactive protein point-of-care testing in general practice to reduce antibiotic prescribing with no differences in symptom duration, patient satisfaction, or reconsultation;

- shared decision making in the management of ARI in general practice to reduce antibiotic prescribing whilst maintaining patient satisfaction and without increasing likelihood of reconsultation;

- procalcitonin-guided management of ARI in general practice and emergency departments to reduce antibiotic prescribing without affecting health-related quality of life and whilst avoiding treatment failure.

Clinicians and health policy makers should note that most of this research was undertaken in high-income countries, and may therefore not be applicable elsewhere. No information on management costs was reported, and therefore no conclusions could be made about cost-effectiveness of interventions. It is likely that cost-effectiveness information would help policymakers and clinicians choose between point-of-care tests for use in their own contexts. Shared decision-making interventions could provide clinicians with skills that can be used outside of respiratory tract infection consultations, which policymakers and clinicians may also want to consider when thinking about value for money.

For the other interventions, including multifaceted interventions, those centred on clinician education, patient information leaflets, and the use of rapid viral diagnostics, the evidence was of low or very low quality across outcomes, therefore we could not confidently draw conclusions about the effects of these interventions. Further primary research is necessary to improve the evidence base in order to be able to make informed decisions about the value of these interventions.

\section{Implications for research}

There is a clear need for further primary research in this area. More high-quality trials that strive to minimise risk of bias in their conduct and fully report their methods are required. Better investigation of the effects of interventions between different settings (differences between primary care and emergency departments, for example) is also needed. Qualitative research can be used to further understand clinicians' behaviours and how they use interventions in everyday practice.

There was a paucity of measurement of secondary outcomes such as prescribing rates and patient outcomes, particularly symptoms and antibiotic resistance, and healthcare resources such as costeffectiveness. These are important outcomes in order to weigh the 
benefits and costs of interventions, and should be measured in future trials.

\section{ACKNOWLEDGEMENTS}

We thank Liz Dooley at the Cochrane Acute Respiratory Infections Group for her advice and guidance in the development of our original protocol and for assistance in undertaking this overview.
The views expressed are those of the authors and not necessarily those of the UK National Health Service, the National Institute of Health Research (NIHR), or the UK Department of Health. 


\section{R E F E R E N C E S}

\section{References to included reviews}

\section{Aabenhus 2014}

Aabenhus R, Jensen JUS, Jørgensen KJ, Hróbjartsson A, Bjerrum L. Biomarkers as point-of-care tests to guide prescription of antibiotics in patients with acute respiratory infections in primary care. Cochrane Database of Systematic Reviews 2014, Issue 11. [DOI: 10.1002/14651858.CD010130.pub2]

\section{Arnold 2005}

Arnold SR, Straus SE. Interventions to improve antibiotic prescribing practices in ambulatory care. Cochrane Database of Systematic Reviews 2005, Issue 4. [DOI: 10.1002/14651858.CD003539.pub2]

\section{Boonacker 2010}

Boonacker CWB, Hoes AW, Dikhoff M, Schilder AGM, Rovers MM. Interventions in health care professionals to improve treatment in children with upper respiratory tract infections. International Journal of Pediatric Otorhinolaryngology 2010;74:1113-21.

\section{Coxeter 2015}

Coxeter P, Del Mar CB, McGregor L, Beller EM, Hoffmann TC. Interventions to facilitate shared decision making to address antibiotic use for acute respiratory infections in primary care. Cochrane Database of Systematic Reviews 2015, Issue 11. [DOI: 10.1002/14651858.CD010907.pub2]

\section{de Bont 2015}

de Bont EGPM, Alink M, Falkenberg FCJ, Dinant G-J, Cals JWL. Patient information leaflets to reduce antibiotic use and reconsultation rates in general practice: a systematic review. BMJ Open 2015;5:e007612. [DOI: 10.1136/ bmjopen-2015-007612]

\section{Doan 2014}

Doan Q, Enarson P, Kissoon N, Klassen TP, Johnson DW. Rapid viral diagnosis for acute febrile respiratory illness in children in the Emergency Department. Cochrane Database of Systematic Reviews 2014, Issue 9. [DOI: 10.1002/14651858.CD006452.pub4]

\section{Huang 2013}

Huang Y, Chen R, Wu T, Wei X, Guo A. Association between pointof-care CRP testing and antibiotic prescribing in respiratory tract infections: a systematic review and meta-analysis of primary care studies. British Journal of General Practice 2013;63(616):e787-94.

\section{Schuetz 2012}

Schuetz P, Müller B, Christ-Crain M, Stolz D, Tamm M, Bouadma $L$, et al. Procalcitonin to initiate or discontinue antibiotics in acute respiratory tract infections. Cochrane Database of Systematic Reviews 2012, Issue 9. [DOI: 10.1002/14651858.CD007498.pub2]

\section{References to excluded reviews}

\section{Andrews 2012}

Andrews T, Thompson M, Buckley DI, Heneghan C, Deyo R, Redmond N, et al. Interventions to influence consulting and antibiotic use for acute respiratory tract infections in children: a systematic review and meta-analysis. PLOS ONE 2012;7(1):e30334. [DOI: 10.1371/journal.pone.0030334]

\section{Arroll 2003}

Arroll B, Kenealy T, Kerse N. Do delayed prescriptions reduce antibiotic use in respiratory tract infections? a systematic review. British Journal of General Practice 2003;53:871-7.

\section{Cooke 2015}

Cooke J, Butler C, Hopstaken R, Drydan MS, McNulty C, Hurding $\mathrm{S}$, et al. Narrative review of primary care point-ofcare testing (POCT) and antibacterial use in respiratory tract infection (RTI). BMJ Open Respiratory Research 2015;2:e000086. [DOI: 10.1136/bmjresp-2015-000086]

\section{Engel 2012}

Engel MF, Paling FP, Hoepelman AIM, van der Meer V, Oosterheert JJ. Evaluating the evidence for the implementation of C-reactive protein measurement in adult patients with suspected lower respiratory tract infection in primary care: a systematic review. Family Practice 2012;29:383-93.

\section{Gross 2001}

Gross PA, Pujat D. Implementing practice guidelines for appropriate antimicrobial usage: a systematic review. Medical Care 2001;39(8):Suppl 2: II-55-69.

\section{Patel 2007}

Patel SJ, Larson EL, Kubin CJ, Saiman L. A review of antimicrobial control strategies in hospitalized and ambulatory pediatric populations. Pediatric Infectious Disease Journal 2007;26:531-7.

\section{Petrozzino 2010}

Petrozzino JJ, Smith C, Atkinson MJ. Rapid diagnostic testing for seasonal influenza: an evidence-based review and comparison with unaided clinical diagnosis. Journal of Emergency Medicine 2010;39(4):476-90.

\section{Ranji 2008}

Ranji SR, Steinman MA, Shojania KG, Gonzales R. Interventions to reduce unnecessary antibiotic prescribing: a systematic review and quantitative analysis. Medical Care 2008;46:847-62.

\section{Rausch 2009}

Rausch S, Flammang M, Haas N, Stein R, Tabouring P, Delvigne $S$, et al. C-reactive protein to initiate or withhold antibiotics in acute respiratory tract infections in adults, in primary care: review. Bulletin de la Société des sciences médicales du Grand-Duché de Luxembourg [Bulletin of the Society of Medical Sciences of the Grand Duchy of Luxembourg] 2009;1:79-87. 


\section{Schuetz 2011}

Schuetz P, Chiappa V, Briel M, Greenwald JL. Procalcitonin algorithms for antibiotic therapy decisions: a systematic review of randomized controlled trials and recommendations for clinical algorithms. Archives of Internal Medicine 2011;171(15):1322-31.

\section{Schuetz 2013}

Schuetz P, Müller B, Christ-Crain M, Stolz D, Tamm M, Bouadma $L$, et al. Procalcitonin to initiate or discontinue antibiotics in acute respiratory tract infections (Review). Evidence-Based Child Health 2013;8(4):1297-371. [DOI: 10.1002/ ebch.1927]

\section{Spurling 2013}

Spurling GKP, Del Mar CB, Dooley L, Foxlee R, Farley R. Delayed antibiotics for respiratory infections. Cochrane Database of Systematic Reviews 2013, Issue 4. [DOI: 10.1002/14651858.CD004417.pub4]

\section{van der Does 2016}

van der Does Y, Rood PPM, Haagsma JA, Patka P, van Gorp ECM, Limper M. Procalcitonin-guided therapy for the initiation of antibiotics in the ED: a systematic review. American Journal of Emergency Medicine 2016;34:1286-93.

\section{van der Velden 2012}

van der Velden AW, Pijpers EJ, Kuyvenhoven MM, TonkinCrine SKG, Little P, Verheij TJM. Effectiveness of physiciantargeted interventions to improve antibiotic use for respiratory tract infections. British Journal of General Practice 2012;62(605):e801-7.

\section{Vodicka 2013}

Vodicka TA, Thompson M, Lucas P, Heneghan C, Blair PS, Buckley DI, et al. Reducing antibiotic prescribing for children with respiratory tract infections in primary care: a systematic review. British Journal of General Practice 2013;63(612):e445-54. [DOI: 10.3399/bjgp13X669167]

\section{Additional references}

\section{ACSQHC 2016}

Australian Commission on Safety and Quality in Health Care (ACSQHC). AURA 2016: First Australian report on antimicrobial use and resistance in human health. www.safetyandquality.gov.au/publications/aura-2016-firstaustralian-report-on-antimicrobial-use-and-resistance-inhuman-health/ (accessed 20 April 2017).

\section{Adriaenssens 2011}

Adriaenssens N, Coenen S, Versporten A, Muller A, Minalu G, Faes $C$, et al. European surveillance of antimicrobial consumption (ESAC): outpatient antibiotic use in Europe (19972009). Journal of Antimicrobial Chemotherapy 2011;66(Suppl 6):vi3-12.

\section{Altiner 2007}

Altiner A, Brockmann S, Sielk M, Wilm S, Wegscheider K, Abholz $\mathrm{HH}$. Reducing antibiotic prescriptions for acute cough by motivating GPs to change their attitudes to communication and empowering patients: a cluster randomized intervention study. Journal of Antimicrobial Chemotherapy 2007;60:638-44.

\section{Andreeva 2014}

Andreeva E, Melbye $\mathrm{H}$. Usefulness of C-reactive protein testing in acute cough/respiratory tract infection: an open clusterrandomised clinical trial with CRP testing in the intervention group. BMC Family Practice 2014;15:80.

\section{Bonner 2003}

Bonner AB, Monroe KW, Talley LI, Klasner AE, Kimberlin DW. Impact of the rapid diagnosis of influenza on physician decision-making and patient management in the pediatric emergency department: results of a randomized, prospective, controlled trial. Pediatrics 2003;112(2):363-7.

\section{Briel 2006}

Briel M, Langewitz W, Tschudi P, Young J, Hugenschmidt C, Bucher HC. Communication training and antibiotic use in acute respiratory tract infections. A cluster randomised controlled trial in general practice. Swiss Medical Weekly 2006;136:241-7.

\section{Briel 2008}

Briel M, Schuetz P, Mueller B, Young J, Schild U, Nusbaumer C, et al. Procalcitonin-guided antibiotic use vs a standard approach for acute respiratory tract infections in primary care. Archives of Internal Medicine 2008;168(18):2000-7.

\section{Burkhardt 2010}

Burkhardt O, Ewig S, Haagen U, Giersdorf S, Hartmann O, Wegscheider $\mathrm{K}$, et al. Procalcitonin guidance and reduction of antibiotic use in acute respiratory tract infection. European Respiratory Journal 2010;36(3):601-7.

\section{Butler 2012}

Butler CC, Simpson SA, Dunstan F, Rollnick S, Cohen D, Gillespie D, et al. Effectiveness of multifaceted educational programme to reduce antibiotic dispensing in primary care: practice based randomised controlled trial. BMJ 2012;344:d8173.

\section{Cals 2009}

Cals JW, Butler CC, Hopstaken RM, Hood K, Dinant GJ. Effect of point of care testing for $C$ reactive protein and training in communication skills on antibiotic use in lower respiratory tract infections: cluster randomised trial. BMJ 2009;338:b1374. [DOI: 10.1136/bmj.b1374]

\section{Cals 2010}

Cals JW, Schot MJ, de Jong SA, Dinant GJ, Hopstaken RM. Pointof-care C-reactive protein testing and antibiotic prescribing for respiratory tract infections: a randomized controlled trial. Annals of Family Medicine 2010;8(2):124-33. [DOI: 10.1370/ afm.1090]

\section{Cals 2011}

Cals JW, Ament AJ, Hood K, Butler CC, Hopstaken RM, Wassink GF, et al. C-reactive protein point of care testing and physician communication skills training for lower respiratory tract infections in general practice: economic evaluation of 
a cluster randomized trial. Journal of Evaluation in Clinical Practice 2011;17(6):1059-69.

\section{Cals 2013}

Cals JW, de Bock L, Beckers PJ, Francis NA, Hopstaken RG, Hood K, et al. Enhanced communication skills and C-reactive protein point-of-care testing for respiratory tract infection: 3.5 year follow-up of a cluster randomized trial. Annals of Family Medicine 2013;11(2):157-64.

\section{CDC 2013}

Centers for Disease Control and Prevention. Antibiotic resistance threats in the United States, 2013. www.cdc.gov/ drugresistance/threat-report-2013/index.html (accessed 16 March 2016).

\section{Christ-Crain 2004}

Christ-Crain M, Jaccard-Stolz D, Bingisser R, Gencay M, Huber P, Tamm M, et al. Effect of procalcitonin guided treatment on antibiotic use and outcome in lower respiratory tract infections: cluster-randomised, single blinded intervention trial. Lancet 2004;1363(9409):600-7.

\section{Christ-Crain 2006}

Christ-Crain M, Stolz D, Bingisser R, Muller C, Miedinger D, Huber PR, et al. Procalcitonin guidance of antibiotic therapy in community-acquired pneumonia: a randomized trial. American Journal of Respiratory and Critical Care Medicine 2006;174(1):84-93.

\section{Christakis 2001}

Christakis DA, Zimmerman FJ, Wright JA, Garrison MM, Rivara FP, Davis RL. A randomized controlled trial of point-of-care evidence to improve the antibiotic prescribing practices for otitis media in children. Pediatrics 2001;107:E15.

\section{Chung 2007}

Chung A, Perera R, Brueggemann AB, Elamin AE, Harnden A, Mayon-White R, et al. Effect of antibiotic prescribing on antibiotic resistance in individual children in primary care: prospective cohort study. BMJ 2007;335(7617):429.

\section{Costelloe 2010}

Costelloe C, Metcalfe C, Lovering A, Mant D, Hay AD. Effect of antibiotic prescribing in primary care on antimicrobial resistance in individual patients: systematic review and metaanalysis. BMJ 2010;340:c2096.

\section{Davey 2017}

Davey P, Marwick CA, Scott CL, Charani E, McNeil K, Brown E, et al. Interventions to improve antibiotic prescribing practices for hospital inpatients. Cochrane Database of Systematic Reviews 2017, Issue 2. [DOI: 10.1002/14651858.CD003543.pub4]

\section{Diederichsen 2000}

Diederichsen HZ, Skamling M, Diederichsen A, Grinsted P, Antonsen S, Petersen PH, et al. Randomised controlled trial of CRP rapid test as a guide to treatment of respiratory infections in general practice. Scandinavian Journal of Primary Health Care 2000;18:39-43.

\section{Doan 2009}

Doan Q, Kissoon N, Whitehouse S, Dobson S, Cochrane D, Schmidt B, et al. A randomized, controlled trial of the impact of early and rapid diagnosis of viral infections in children brought to an Emergency Department with febrile respiratory tract illnesses. Journal of Pediatrics 2009;154(1):91-5.

\section{Finkelstein 2001}

Finkelstein JA, Davis RL, Dowell SF, Metlay JP, Soumerai SB, Rifas-Shiman SL, et al. Reducing antibiotic use in children: a randomized trial in 12 practices. Pediatrics 2001;108:1-7.

\section{Flottorp 2002}

Flottorp S, Oxman AD, Havelsrud K, Treweek S, Herrin J. Cluster randomized controlled trial of tailored interventions to improve the management of urinary tract infections in women and sore throat. BMJ 2002;325:367-72.

\section{Francis 2009}

Francis NA, Butler CC, Hood K, Simpson S, Wood F, Nuttall J. Effect of using an interactive booklet about childhood respiratory tract infections in primary care consultations on reconsulting and antibiotic prescribing: a cluster randomised controlled trial. BMJ 2009;339:374-6.

\section{Gonzales 2011}

Gonzales R, Aagaard EM, Camargo CA Jr, Ma OJ, Plautz M, Maselli J, et al. C-reactive protein testing does not decrease antibiotic use for acute cough illness when compared to a clinical algorithm. Journal of Emergency Medicine 2011;41(1):1-7.

\section{Goossens 2005}

Goossens H, Ferech M, Vander Stichele R, Elseviers M, ESAC Project Group. Outpatient antibiotic use in Europe and association with resistance: a cross-national database study. Lancet 2005;365(9459):579-87.

\section{Gulliford 2014}

Gulliford MC, Dregan A, Moore MV, Ashworth M, van Staa T, McCann G, et al. Continued high rates of antibiotic prescribing to adults with respiratory tract infection: survey of $568 \mathrm{UK}$ general practices. BMJ Open 2014;4:e006245.

\section{Guyatt 2008}

Guyatt GH, Oxman AD, Kunz R, Vist GE, Falck-Ytter Y, Schünemann HJ, GRADE Working Group. Rating quality of evidence and strength of recommendations: what is "quality of evidence" and why is it important to clinicians?. BMJ 2008;336(7651):995-8

\section{Higgins 2011}

Higgins JPT, Green S (editors). Cochrane Handbook for Systematic Reviews of Interventions Version 5.1.0 [updated March 2011]. The Cochrane Collaboration, 2011. Available from handbook.cochrane.org.

\section{Hu 2016}

Hu Y, Walley J, Chou R, Tucker JD, Harwell JI, Wu X, et al. Interventions to reduce childhood antibiotic prescribing for upper respiratory infections: systematic review and 
meta-analysis. Journal of Epidemiology \& Community Health 2016;70:1162-70.

\section{Huttner 2013}

Huttner A, Harbarth S, Carlet J, Cosgrove S, Goossens H, Holmes A, et al. Antimicrobial resistance: a global view from the 2013 World Healthcare-Associated Infections Forum. Antimicrobial Resistance and Infection Control 2013;2:31.

\section{Kristoffersen 2009}

Kristoffersen KB, Sogaard OS, Wejse C, Black FT, Greve T, Tarp B, et al. Antibiotic treatment interruption of suspected lower respiratory tract infections based on a single procalcitonin measurement at hospital admission - a randomized trial. Clinical Microbiology and Infection 2009;15(5):481-7.

\section{Lancet 2009}

Urgently needed: new antibiotics. Lancet 2009;374(9705):1868.

\section{Little 2013}

Little P, Stuart B, Francis N, Tonkin-Crine S, Douglas E, Anthierens $S$, et al. The effect of web-based training in communication skills and an interactive patient booklet and the use of a CRP point of care test in acute respiratory tract infection (RTI): a multi-national cluster randomised factorial controlled trial. Lancet 2013;382(9899):1175-82.

\section{Long 2009}

Long W, Deng XQ, Tang JG, Xie J, Zhang YC, Zhang Y, et al. Procalcitonin-guidance for reduction of antibiotic use in low-risk outpatients with community acquired pneumonia. Zhonghua Nei Ke Za Zhi 2009;48(3):216-9.

\section{Long 2011}

Long W, Deng X, Zhang Y, Lu G, Xie J, Tang J. Procalcitoninguidance for reduction of antibiotic use in low-risk outpatients with community acquired pneumonia. Respirology 2011;76(1):266-9.

\section{Légaré 2011}

Légaré $F$, Labrecque $M$, LeBlanc A, Njoya M, Laurier C, Cote L, et al. Training family physicians in shared decision making for the use of antibiotics for acute respiratory infections: a pilot clustered randomized controlled trial. Health Expectations 2011;14(Suppl 1):96-110.

\section{Légaré 2012}

Légaré F, Labrecque M, Cauchon M, Castel J, Turcotte S, Grimshaw J. Training family physicians in shared decision making to reduce the overuse of antibiotics in acute respiratory infections: a cluster randomized trial. Canadian Medical Association Journal 2012;184:E726-34.

\section{Macfarlane 1997}

Macfarlane JT, Holmes WF, Macfarlane RM. Reducing reconsultations for acute lower respiratory tract illness with an information leaflet: a randomized controlled study of patients in primary care. British Journal of General Practice 1997;47:719-22.

\section{Mainous 2000}

Mainous AG 3rd, Hueston WJ, Love MM, Evans ME, Finger R. An evaluation of statewide strategies to reduce antibiotic overuse. Family Medicine 2000;32:22-9.

\section{Makoul 2006}

Makoul G, Clayman ML. An integrative model of shared decision making in medical encounters. Patient Education and Counseling 2006;60:301-12.

\section{Malhotra-Kumar 2007}

Malhotra-Kumar S, Lammens C, Coenen S, Van Herck K, Goossens H. Effect of azithromycin and clarithromycin therapy on pharyngeal carriage of macrolide-resistant streptococci in healthy volunteers: a randomised, double-blind, placebocontrolled study. Lancet 2007;369(9560):482-90.

\section{Martinez-Gonzalez 2017}

Martinez-Gonzalez NA, Coenen S, Plate A, Colliers A, Rosemann T, Senn O, et al. The impact of interventions to improve the quality of prescribing and use of antibiotics in primary care patients with respiratory tract infections: a systematic review protocol. BMJ Open 2017;7(6):e016253.

\section{McDonagh 2016}

McDonagh M, Peterson K, Winthrop K, Cantor A, Holzhammer B, Buckley DI. Improving antibiotic prescribing for uncomplicated acute respiratory tract infections. Rockville (MD): Agency for Healthcare Research and Quality; January 2016. Comparative Effectiveness Review No. 163. (Prepared by the Pacific Northwest Evidence-based Practice Center under Contract No. 290-2012-00014-I.) AHRQ Publication Number: 15(16)-EHC033EF..

\section{Mclsaac 1998}

Mclsaac WJ, Goel V. Effect of an explicit decision-support tool on decisions to prescribe antibiotics for sore throat. Medical Decision Making 1998;18:220-8.

\section{Mclsaac 2002}

Mclsaac WJ, Goel V, To T, Permaul JA, Low DE. Effect on antibiotic prescribing of repeated clinical prompts to use a sore throat score: lessons from a failed community intervention study. Journal of Family Practice 2002;51:339-44.

\section{Melbye 1995}

Melbye H, Aaraas I, Fleten N, Kolstrup N, Mikalsen J-I. The value of C-reactive protein testing in suspected lower respiratory tract infections. A study from general practice on the effect of a rapid test on antibiotic research and course of the disease in adults [Nytten av å teste C-reaktivt protein ved mulig nedre luftveisinfeksjon. En undersøkelse fran allmennpraksis av en hurtigtests innvirkning på antibiotikaforskrivning og sykdomsforløp hos voksne]. Tidsskrift for Norske Laegeforeningen 1995;115(13):1610-5.

\section{Moore 2015}

Moore G, Audrey S, Barker M, Bond L, Bonell C, Hardeman W, et al. Process evaluation of complex interventions: Medical Research Council guidance. BMJ 2015;350:h1258. 


\section{O'Neill 2014}

O'Neill J, Davies S, Rex J, White LJ, Murray R. Antimicrobial resistance: tackling a crisis for the health and wealth of nations. amr-review.org/sites/default/files/AMR\%20Review\%20Paper \%20-\%20Tackling\%20a\%20crisis\%20for\%20the\%20health \%20and\%20wealth\%20of\%20nations_1.pdf (accessed 20 April 2017).

\section{O'Sullivan 2016}

O'Sullivan JW, Harvey RT, Glasziou PP, McCullough A. Written information for patients (or parents of child patients) to reduce the use of antibiotics for acute upper respiratory tract infections in primary care. Cochrane Database of Systematic Reviews 2016, Issue 11. [DOI: 10.1002/14651858.CD011360.pub2]

\section{PHE 2013}

Public Health England. UK One Health Report. Joint report on human and animal antibiotic use, sales and resistance, 2013. www.gov.uk/government/uploads/system/uploads/ attachment_data/file/447319/One_Health_Report_ July2015.pdf (accessed 13 June 2016).

\section{Poehling 2006}

Poehling KA, Zhu Y, Tang YW, Edwards K. Accuracy and impact of a point-of-care rapid influenza test in young children with respiratory illnesses. Archives of Pediatrics and Adolescent Medicine 2006;160(7):713-8.

\section{RevMan 2014 [Computer program]}

The Nordic Cochrane Centre, The Cochrane Collaboration. Review Manager (RevMan). Version 5.3. Copenhagen: The Nordic Cochrane Centre, The Cochrane Collaboration, 2014.

\section{Schuetz 2009}

Schuetz P, Christ-Crain M, Thomann R, Falconnier C, Wolbers M, Widmer I, et al. Effect of procalcitonin-based guidelines vs standard guidelines on antibiotic use in lower respiratory tract infections: the ProHOSP randomized controlled trial. JAMA 2009;302(10):1059-66.

\section{Shapiro 2014}

Shapiro DJ, Hicks LA, Pavia AT, Hersh AL. Antibiotic prescribing for adults in ambulatory care in the USA, 2007-09. Journal of Antimicrobial Chemotherapy 2014;69(1):234-40.

\section{Smith 2013}

Smith R, Coast J. The true cost of antimicrobial resistance. BMJ 2013;346:f1493.

\section{Smith 2014}

Smith SM, Fahey T, Smucny J, Becker LA. Antibiotics for acute bronchitis. Cochrane Database of Systematic Reviews 2014, Issue 3. [DOI: 10.1002/14651858.CD000245.pub3]

\section{Spellberg 2013}

Spellberg B, Bartlett JG, Gilbert DN. The future of antibiotics and resistance. New England Journal of Medicine 2013;368(4):299-302.

\section{Spinks 2013}

Spinks A, Galsziou PP, Del Mar CB. Antibiotics for sore throat. Cochrane Database of Systematic Reviews 2013, Issue 11. [DOI: 10.1002/14651858.CD000023.pub4]

\section{Stolz 2007}

Stolz D, Christ-Crain M, Bingisser R, Leuppi J, Miedinger D, Muller C, et al. Antibiotic treatment of exacerbations of COPD: a randomized, controlled trial comparing procalcitonin-guidance with standard therapy. Chest 2007;131(1):9-19.

\section{Tonkin-Crine 2011}

Tonkin-Crine S, Yardley L, Little P. Antibiotic prescribing for acute respiratory tract infections in primary care: a systematic review and meta-ethnography. Journal of Antimicrobial Chemotherapy 2011;66(10):2215-23.

\section{Van Boeckel 2014}

Van Boeckel TP, Gandra S, Ashok A, Caudron Q, Grenfell BT, Levin SA, et al. Global antibiotic consumption 2000 to 2010: an analysis of national pharmaceutical sales data. Lancet Infectious Diseases 2014;14(8):742-50.

\section{Venekamp 2015}

Venekamp RP, Sanders S, Glaszioiu PP, Del Mar CB, Rovers MM. Antibiotics for acute otitis media in children. Cochrane Database of Systematic Reviews 2015, Issue 6. [DOI: 10.1002/14651858.CD000219.pub4]

\section{Welschen 2004}

Welschen I, Kuyvenhoven MM, Hoes AW, Verheij TJ. Effectiveness of a multiple intervention to reduce antibiotic prescribing for respiratory tract symptoms in primary care: randomised controlled trial. BMJ 2004;329:431.

\section{Whiting 2016}

Whiting P, Savović J, Higgins JPT, Caldwell DM, Reeves BC, Shea B, et al. ROBIS: A new tool to assess risk of bias in systematic reviews was developed. Journal of Clinical Epidemiology 2016;69:225-34.

\section{WHO 2015}

World Health Organization. Global action plan on antimicrobial resistance, 2015. apps.who.int/iris/ bitstream/10665/193736/1/9789241509763_eng.pdf?ua=1 (accessed 13 June 2016).

\section{Wilson 2002}

Wilson EJ. Realities of practice: development and implementation of clinical practice guidelines for acute respiratory infections in young children (PhD thesis). The Australian National University 2002.

\section{Yardley 2013}

Yardley L, Douglas E, Anthierens S, Tonkin-Crine S, O'Reilly G, Stuart B, et al. Evaluation of a web-based intervention to reduce antibiotic prescribing in six European countries; quantitative process analysis of the GRACE/INTRO randomised controlled trial. Implementation Science 2013;8:134. 


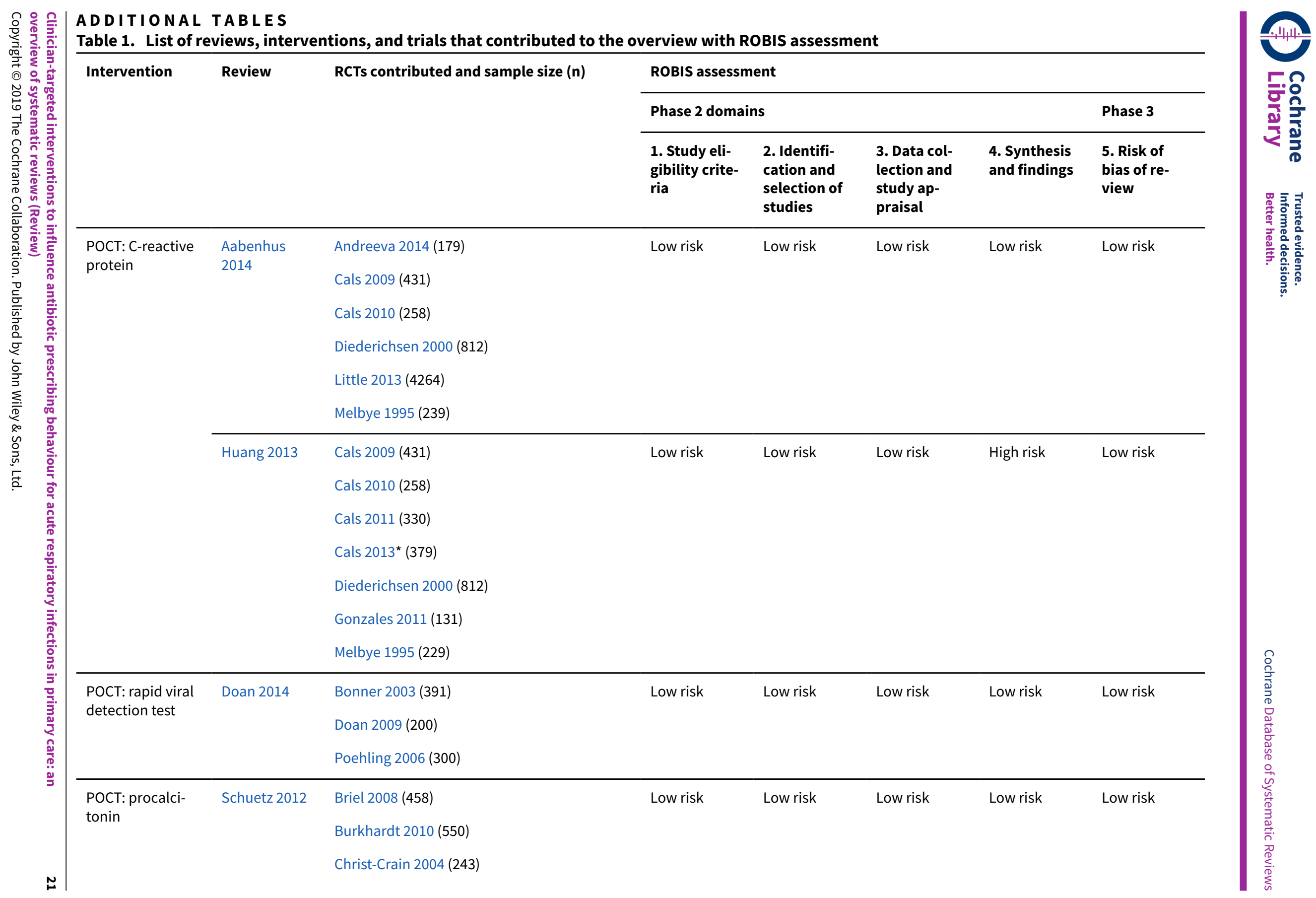




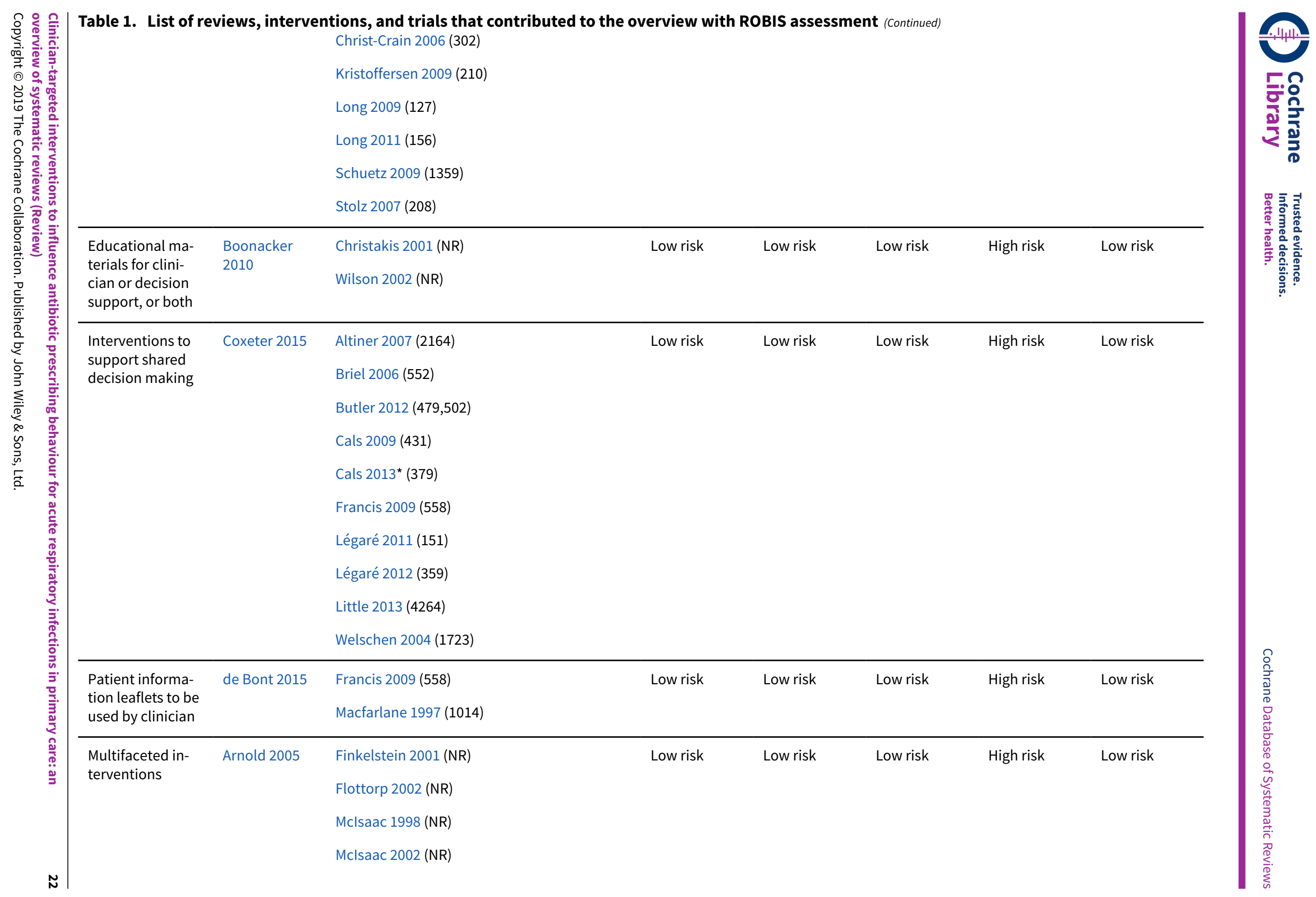




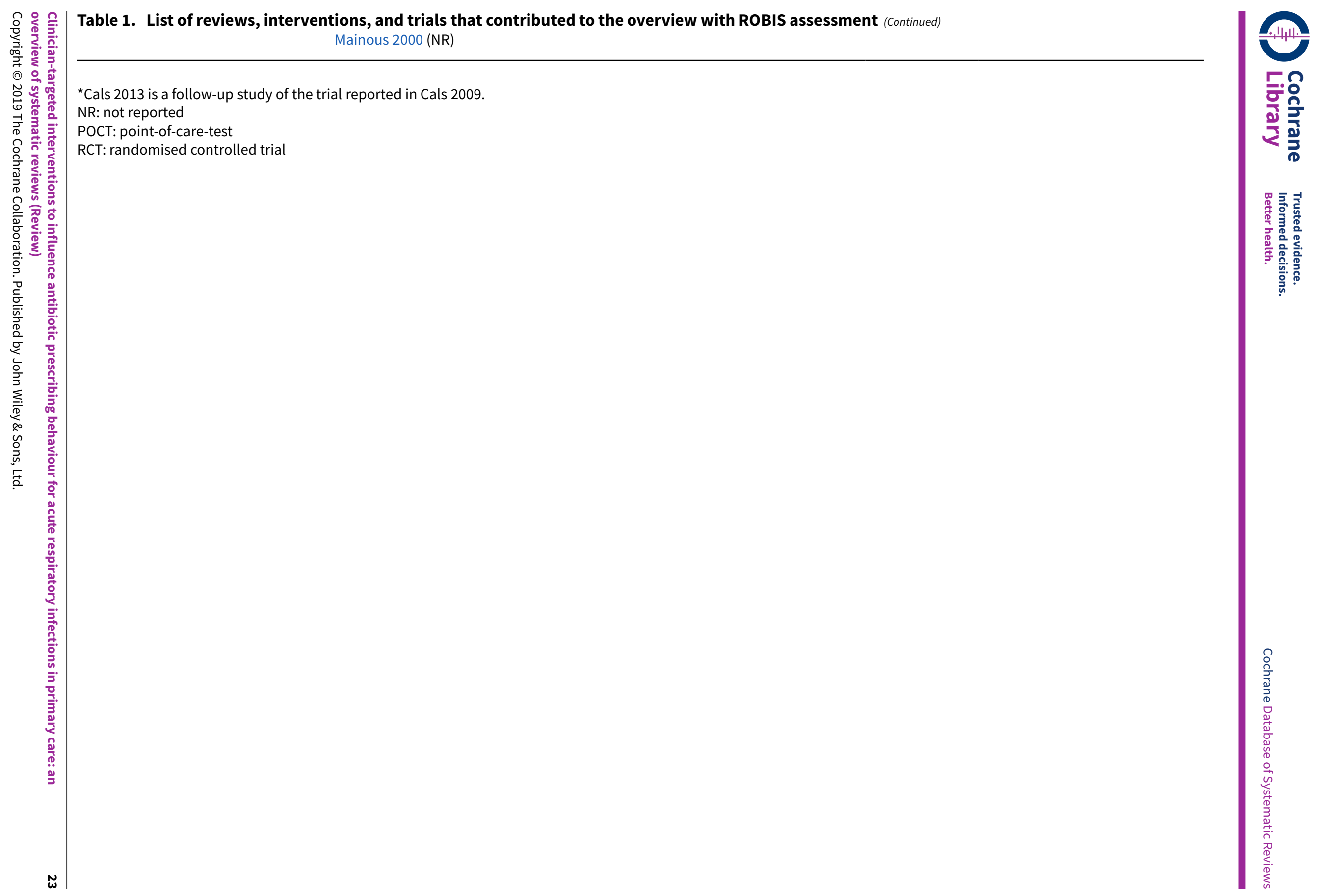


Table 2. Characteristics of excluded reviews

\begin{tabular}{ll}
\hline Reason for exclusion & Reviews excluded ( $=\mathbf{1 5})$ \\
\hline Does not include RCTs including parallel-group, cluster, or factorial RCTs & Petrozzino 2010 \\
\hline $\begin{array}{l}\text { Does not include studies that include patients presenting to primary care with } \\
\text { acute respiratory infection }\end{array}$ & Patel 2007 \\
\hline $\begin{array}{l}\text { Does not include interventions aimed at health professional with the primary } \\
\text { goal of reducing antibiotic prescribing }\end{array}$ & $\begin{array}{l}\text { Andrews 2012; Arroll 2003; Petrozzino 2010; Spurl- } \\
\text { ing 2013 }\end{array}$ \\
\hline $\begin{array}{l}\text { Does not investigate the effect of the intervention on antibiotic prescribing } \\
\text { compared to usual care or control }\end{array}$ & $\begin{array}{l}\text { Andrews 2012; Arroll 2003; Rausch 2009; Schuetz } \\
\text { 2011; Spurling 2013 }\end{array}$ \\
\hline $\begin{array}{l}\text { Duplication of included review } \\
\text { Data were not reported at an individual-study basis. }\end{array}$ & $\begin{array}{l}\text { Schuetz 2013 (duplicate of included Cochrane re- } \\
\text { view Schuetz 2012) }\end{array}$ \\
\hline No novel coverage in addition to included Cochrane Review & Gross 2001; van der Velden 2012 \\
\hline Rated as high risk in ROBIS quality assessment & $\begin{array}{l}\text { Cooke 2015; Engel 2012 (both fully overlap with } \\
\text { Aabenhus 2014 in terms of included trials) }\end{array}$ \\
\hline
\end{tabular}

$\mathrm{RCT}$ : randomised controlled trial 


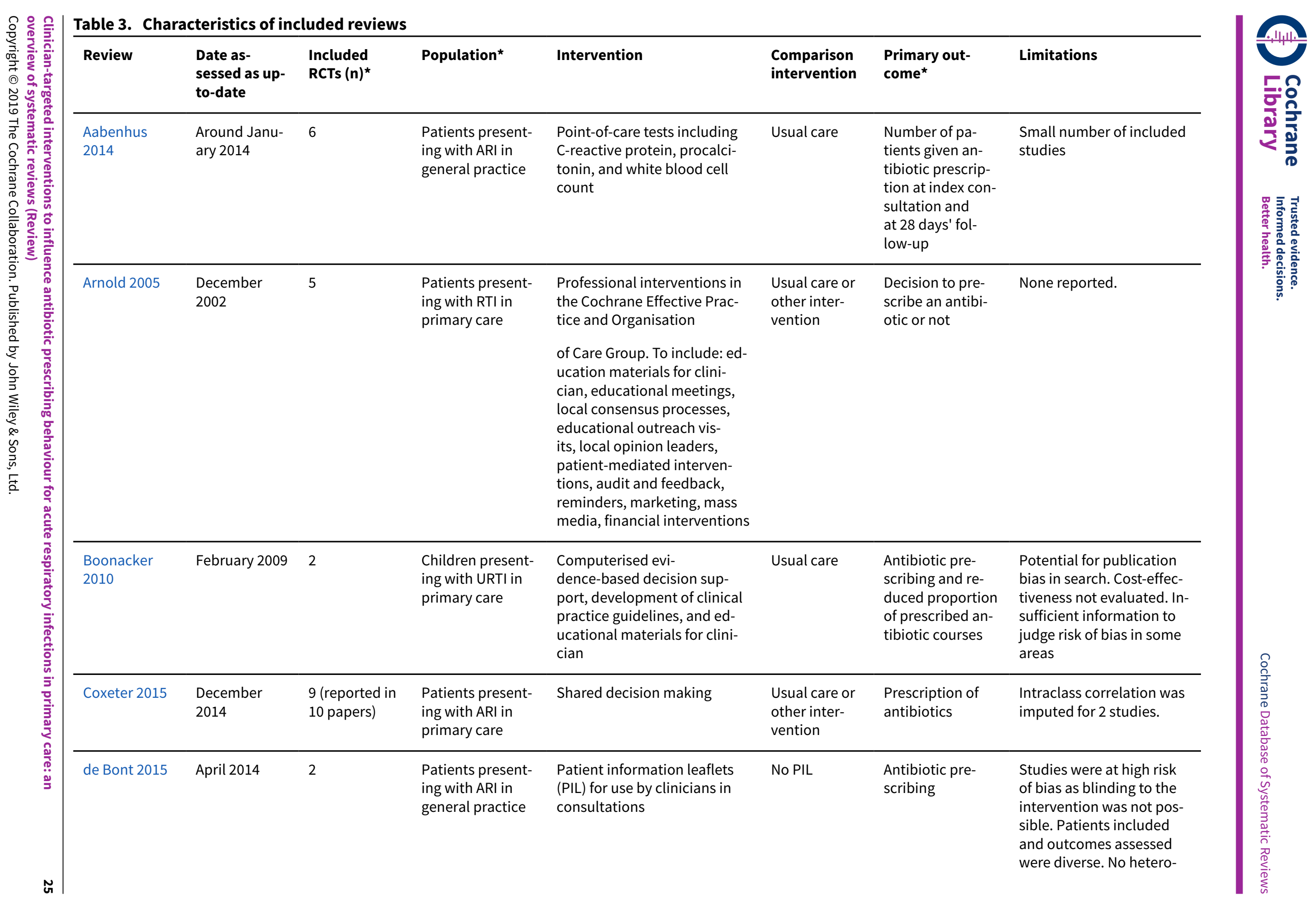




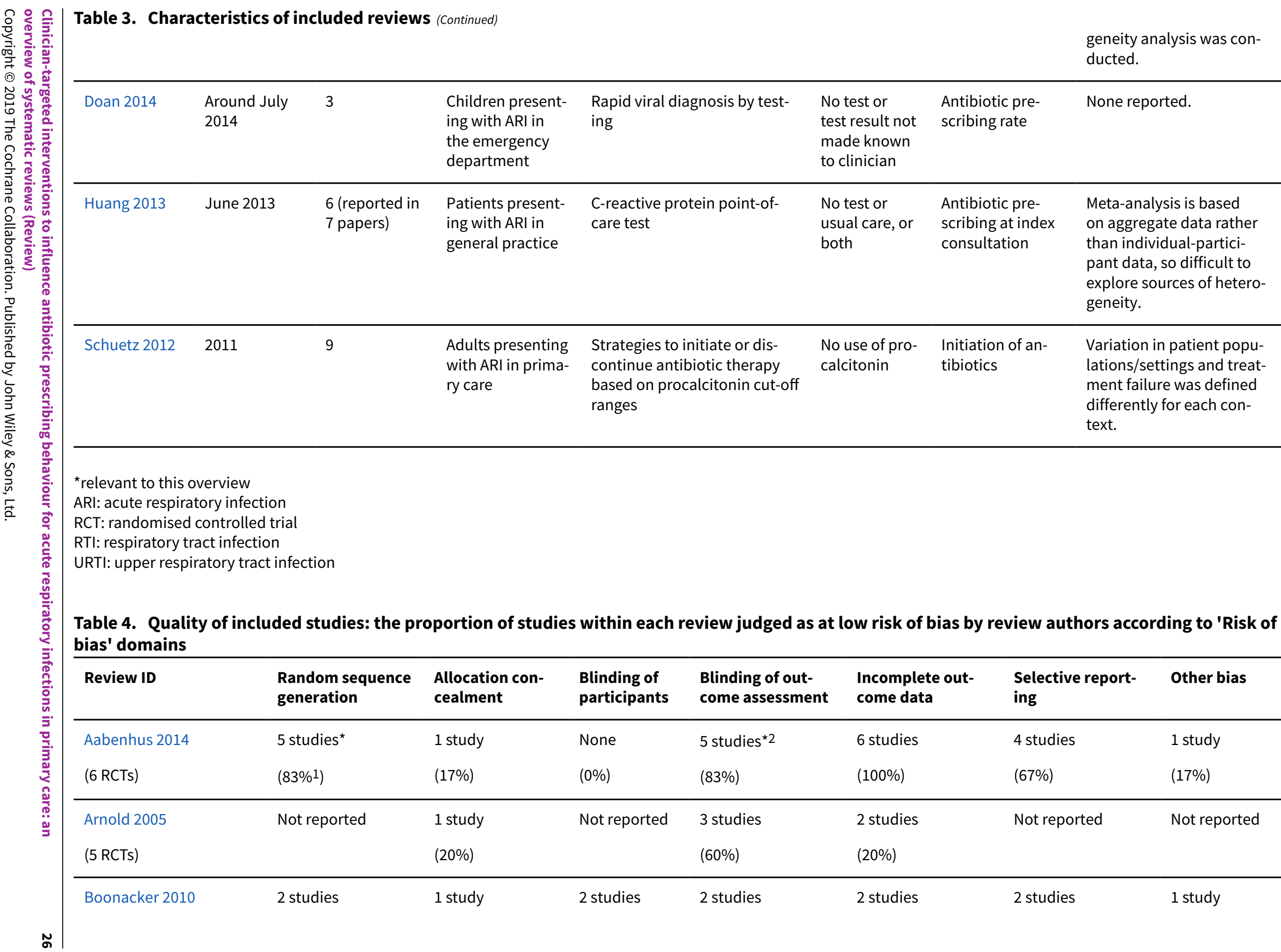




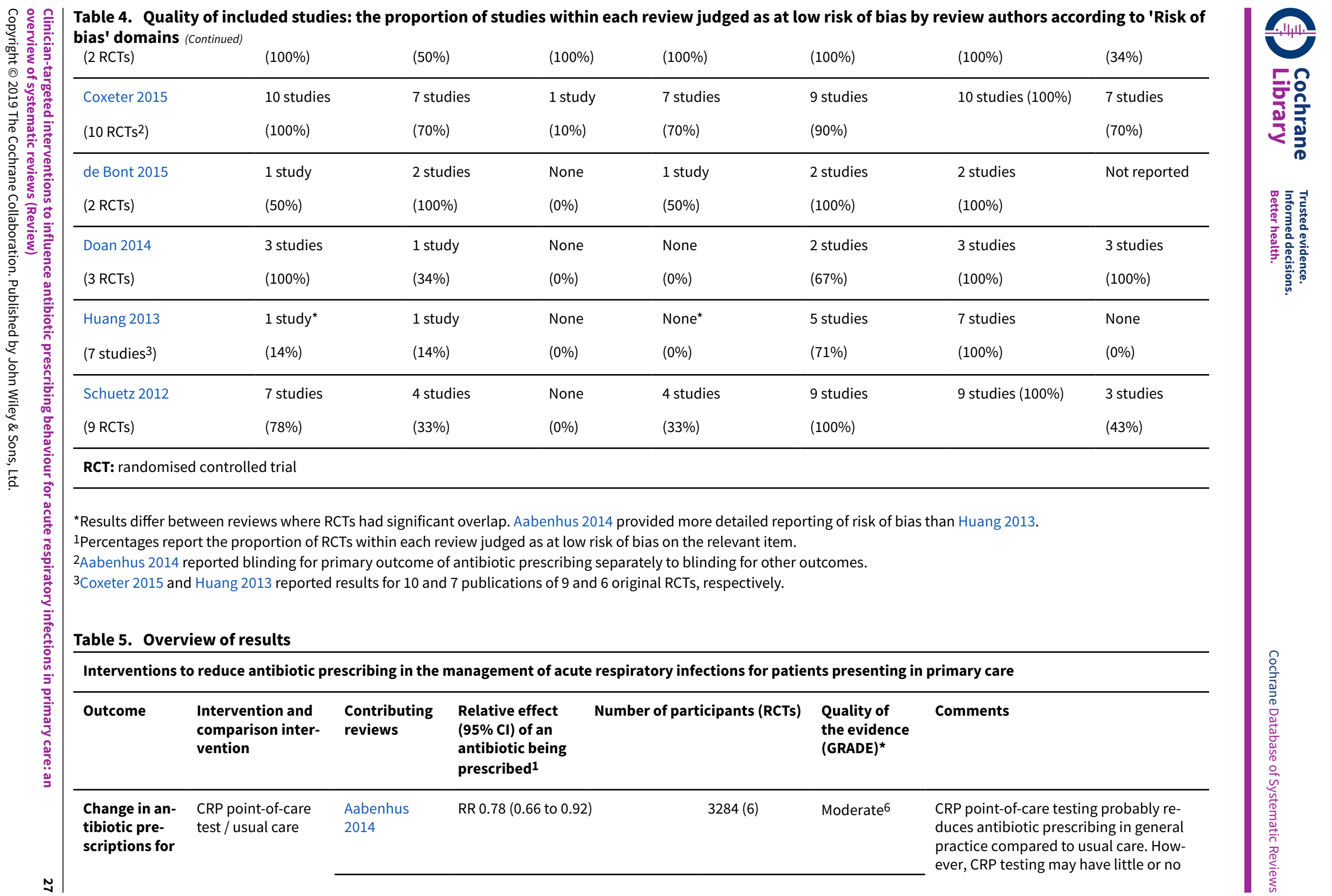


5. Overview of results (Continued)

\section{ARI (at con-}

sultation)
Huang 2013
General practice setting (individual trials reported):

RR 0.57 (0.44 to 0.74 )

RR $0.58(0.45$ to 0.74
$330(1)$

$379(1)$

Moderate $^{3 *}$

effect on prescribing in emergency departments.

$131(1)$

Emergency department setting:

RR 1.23 (0.76 to 1.99 )

\begin{tabular}{|c|c|c|c|c|c|}
\hline $\begin{array}{l}\text { Rapid viral diagno- } \\
\text { sis / usual care }\end{array}$ & Doan 2014 & RR 0.86 (0.61 to 1.22 ) & $891(3)$ & Low3,6* & $\begin{array}{l}\text { Rapid viral diagnosis may have little or } \\
\text { no effect on antibiotic prescribing com- } \\
\text { pared to usual care. }\end{array}$ \\
\hline $\begin{array}{l}\text { Procalcitonin-guid- } \\
\text { ed management / } \\
\text { usual care }\end{array}$ & Schuetz 2012 & $\begin{array}{l}\text { General practice setting: } \\
\text { adjusted OR } 0.10 \text { ( } 0.07 \text { to } 0.14 \text { ) } \\
\text { Emergency department setting: } \\
\text { adjusted OR } 0.34 \text { ( } 0.28 \text { to } 0.43 \text { ) }\end{array}$ & $\begin{array}{l}1008(2) \\
2605(7)\end{array}$ & $\begin{array}{l}\text { Moderate }^{3} \\
\text { Moderate }^{3}\end{array}$ & $\begin{array}{l}\text { Procalcitonin-guided management } \\
\text { probably reduces antibiotic prescribing } \\
\text { in general practice and the emergency } \\
\text { department compared to usual care. }\end{array}$ \\
\hline $\begin{array}{l}\text { Clinician education } \\
\text { and decision sup- } \\
\text { port / usual care }\end{array}$ & $\begin{array}{l}\text { Boonacker } \\
2010\end{array}$ & $\begin{array}{l}\text { Difference in behaviour change } \\
-12 \%(0.095) \\
\text { OR } 0.60 \text { ( } 0.43 \text { to } 0.83)\end{array}$ & $\begin{array}{l}\text { Not reported } \\
(1) \\
\text { Not reported } \\
(1)\end{array}$ & Very low3,5,6* & $\begin{array}{l}\text { We are uncertain about whether clini- } \\
\text { cian education and decision support re- } \\
\text { duces antibiotic prescribing compared } \\
\text { to usual care. }\end{array}$ \\
\hline $\begin{array}{l}\text { Patient informa- } \\
\text { tion leaflets / usual } \\
\text { care }\end{array}$ & de Bont 2015 & $\begin{array}{l}\text { RR } 0.47 \text { (0.36 to } 0.64) \\
\text { RR } 1.15 \text { (0.89 to } 1.48 \text { ) }\end{array}$ & $\begin{array}{l}558(1) \\
1014(1)\end{array}$ & Very low3,4,6* & $\begin{array}{l}\text { We are uncertain as to whether patient } \\
\text { information leaflets reduce antibiotic } \\
\text { prescribing compared to usual care. }\end{array}$ \\
\hline $\begin{array}{l}\text { Shared decision } \\
\text { making / usual care }\end{array}$ & Coxeter 2015 & $\begin{array}{l}\text { No pooled analysis of all trials: } \\
\text { OR } 0.44 \text { ( } 0.26 \text { to } 0.75) \\
\text { RR } 0.64 \text { ( } 0.49 \text { to } 0.84) \\
\text { adjusted risk difference }-18.44 \\
\text { (-27.24 to }-9.65)\end{array}$ & $\begin{array}{l}3274(3) \\
4623(2) \\
481,807(4)\end{array}$ & Moderate 3 & $\begin{array}{l}\text { Shared decision making probably re- } \\
\text { duces antibiotic prescribing compared } \\
\text { to usual care. }\end{array}$ \\
\hline Multifaceted interv & ntions & & & & \\
\hline $\begin{array}{l}\text { Printed education- } \\
\text { al materials for } \\
\text { clinicians and re- }\end{array}$ & Arnold 2005 & $\begin{array}{l}\text { Individual trials reported: } \\
\text { OR } 0.44 \text { ( } 0.21 \text { to } 0.92 \text { ) }\end{array}$ & $\begin{array}{l}\text { Not reported } \\
(1)\end{array}$ & Very low3,4,6* & $\begin{array}{l}\text { We are uncertain as to whether printed } \\
\text { educational materials reduce antibiotic } \\
\text { prescribing compared to usual care. }\end{array}$ \\
\hline
\end{tabular}




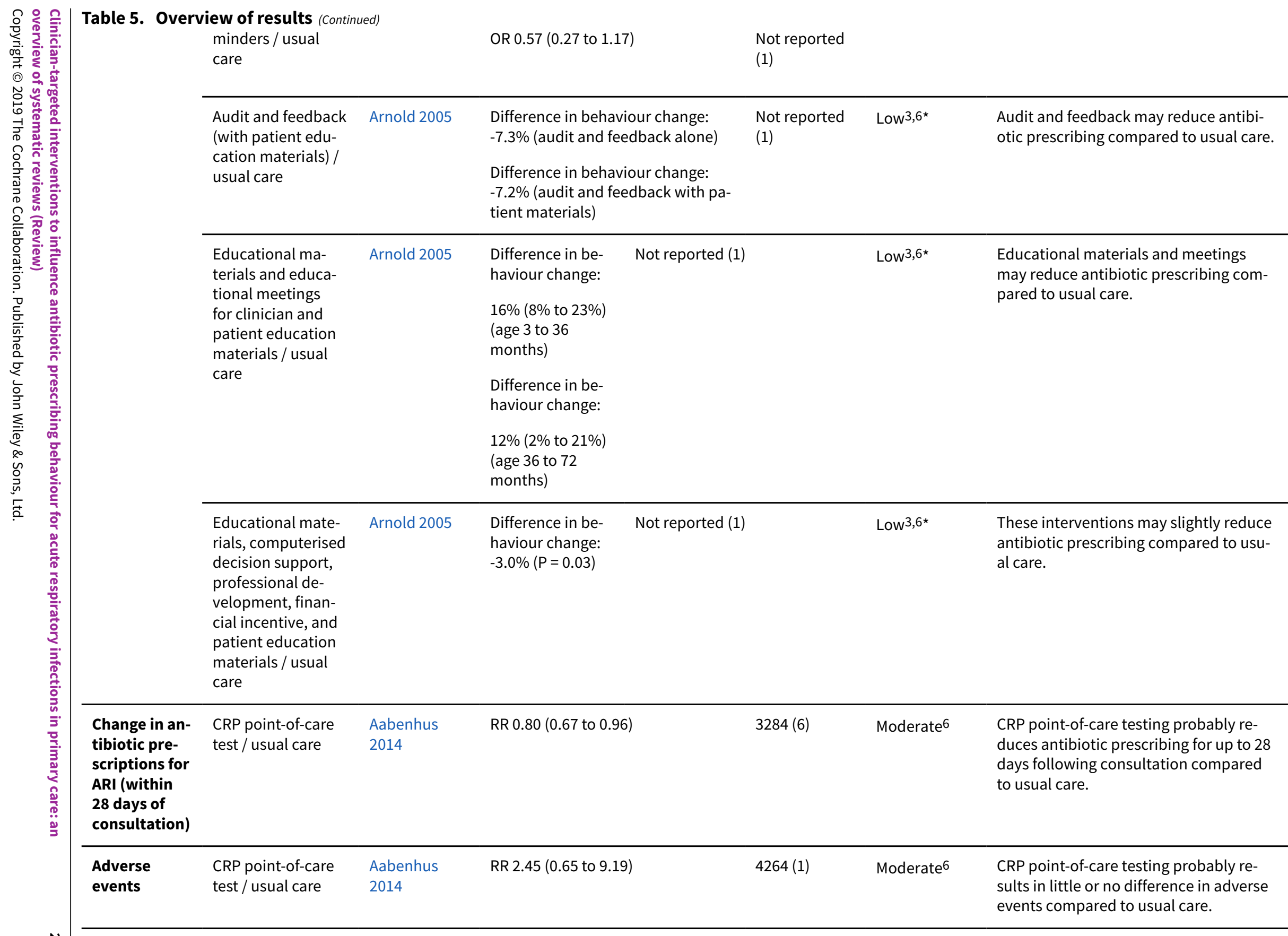


Table 5. Overview of results (Continued)

Symptom CRP point-of-care Aabenhus At 7 days: RR 1.03 (0.93 to 1.14) 1309 (3) Moderate $6 \quad$ CRP point-of-care testing probably re-

dest/usual care 2014

At 28 days: RR 0.94 (0.69 to 1.28$)$

849 (3)

tom duration or severity compared to

usual care.

\begin{tabular}{|c|c|c|c|c|c|}
\hline $\begin{array}{l}\text { Health-relat- } \\
\text { ed quality of } \\
\text { life }\end{array}$ & $\begin{array}{l}\text { Procalcitonin-guid- } \\
\text { ed management / } \\
\text { usual care }\end{array}$ & Schuetz 2012 & $\begin{array}{l}\text { Adjusted difference in days } 0.05 \text {, } \\
-0.46 \text { to } 0.56, P=0.854\end{array}$ & $1008(2)$ & Moderate $^{3}$ \\
\hline
\end{tabular}

Procalcitonin-guided management probably results in little or no difference

in health-related quality of life compared to usual care.

\begin{tabular}{|c|c|c|c|c|c|c|}
\hline \multirow[t]{2}{*}{$\begin{array}{l}\text { Patient satis- } \\
\text { faction }\end{array}$} & $\begin{array}{l}\text { CRP point-of-care } \\
\text { test / usual care }\end{array}$ & $\begin{array}{l}\text { Aabenhus } \\
2014\end{array}$ & RR 0.79 (0.57 to 1.08$)$ & $689(2)$ & Moderate 6 & $\begin{array}{l}\text { CRP point-of-care testing probably re- } \\
\text { sults in little or no difference in patient } \\
\text { satisfaction compared to usual care. }\end{array}$ \\
\hline & $\begin{array}{l}\text { Shared decision } \\
\text { making / usual care }\end{array}$ & Coxeter 2015 & RR 0.86 (0.57 to 1.30 ) & $1110(2)$ & Low $^{3,6}$ & $\begin{array}{l}\text { Shared decision making may result in } \\
\text { little or no difference in patient satisfac- } \\
\text { tion compared to usual care. }\end{array}$ \\
\hline
\end{tabular}

\begin{tabular}{|c|c|c|c|c|c|c|c|}
\hline \multirow[t]{6}{*}{$\begin{array}{l}\text { Management } \\
\text { failure - re- } \\
\text { consultation } \\
\text { and treat- } \\
\text { ment failure }\end{array}$} & \multirow{2}{*}{$\begin{array}{l}\text { CRP point-of-care } \\
\text { test / usual care } \\
\text { Shared decision } \\
\text { making / usual care }\end{array}$} & $\begin{array}{l}\text { Aabenhus } \\
2014\end{array}$ & \multicolumn{2}{|c|}{ RR 1.08 (0.93 to 1.27 ) } & $5132(4)$ & Moderate 6 & \multirow{2}{*}{$\begin{array}{l}\text { CRP point-of-care testing probably re- } \\
\text { sults in little or no difference in recon- } \\
\text { sultation compared with usual care at } \\
28 \text { days' follow-up. } \\
\text { Shared decision making probably re- } \\
\text { sults in little or no difference in recon- } \\
\text { sultation compared to usual care. }\end{array}$} \\
\hline & & Coxeter 2015 & RR 0.87 (0.74 to 1. & & $1860(4)$ & Moderate 3 & \\
\hline & $\begin{array}{l}\text { Patient informa- } \\
\text { tion leaflets / usual } \\
\text { care }\end{array}$ & de Bont 2015 & $\begin{array}{l}\text { Individual trials } \\
\text { reported: } \\
\text { RR } 0.80 \text { ( } 0.52 \text { to } \\
1.21 \text { ) }\end{array}$ & $\begin{array}{l}558(1) \\
1014(1)\end{array}$ & & Very low3,4,6* & $\begin{array}{l}\text { We are uncertain as to whether patient } \\
\text { intervention leaflets result in a differ- } \\
\text { ence in reconsultation compared to usu- } \\
\text { al care. }\end{array}$ \\
\hline & & & $\begin{array}{l}\text { RR } 0.70 \text { ( } 0.53 \text { to } \\
0.91 \text { ) }\end{array}$ & & & & \\
\hline & $\begin{array}{l}\text { Rapid viral diagno- } \\
\text { sis / usual care }\end{array}$ & Doan 2014 & $\begin{array}{l}\text { RR } 0.86 \text { ( } 0.59 \text { to } \\
1.25)\end{array}$ & $200(1)$ & & $\operatorname{Low}^{3,6 *}$ & $\begin{array}{l}\text { Rapid viral diagnostics may result in lit- } \\
\text { tle or no difference in reconsultation rel- } \\
\text { ative to usual care. }\end{array}$ \\
\hline & $\begin{array}{l}\text { Procalcitonin-guid- } \\
\text { ed management / } \\
\text { usual care }\end{array}$ & Schuetz 2012 & $\begin{array}{l}\text { Treatment failure } \\
\text { in general prac- } \\
\text { tice }^{2} \text { : }\end{array}$ & $\begin{array}{l}1008(2) \\
2605(7)\end{array}$ & & Moderate $^{3}$ & $\begin{array}{l}\text { Procalcitonin-guided management } \\
\text { probably results in little or no difference } \\
\text { in treatment failure in general practice }\end{array}$ \\
\hline
\end{tabular}

in general prac-

tice ${ }^{2}$

$2605(7)$ 
Table 5. Overview of results (Continued)

\section{adjusted OR 0.95 \\ (0.73 to 1.24 )}

Treatment failure

in emergency de-

partment 2

adjusted OR 0.76

(0.61 to 0.95$)$
Procalcitonin-guided management probably reduces treatment failure in the emergency department compared to usual care.

GRADE quality of evidence and definitions

High quality: Further research is very unlikely to change our confidence in the estimate of effect.

Moderate quality: Further research is likely to have an important impact on our confidence in the estimate of effect and may change the estimate.

Low quality: Further research is very likely to have an important impact on our confidence in the estimate of effect and is likely to change the estimate.

Very low quality: Any estimate of effect is very uncertain.

*GRADE criteria were applied retrospectively to outcomes when GRADE was not used by the original review authors.

ARI: acute respiratory infection; Cl: confidence interval; CRP: C-reactive protein; OR: odds ratio; $\mathbf{R C T}$ : randomised controlled trial; RR: risk ratio

1 Effect estimates are shown as reported in the original reviews. Multiple effect estimates are reported for some outcomes when reviews did not pool data from trials but reported individual trials separately.

2Schuetz 2012 defined treatment failure in primary care as death, hospitalisation, ARI-specific complications (e.g. empyema for lower ARIs, meningitis for upper ARIs), recurrent or worsening infection, and still having ARI-associated discomfort at 30 days. Treatment failure in the emergency setting was defined as death, intensive care unit admission, rehospitalisation after index hospital discharge, ARI-associated complications (e.g. empyema or acute respiratory distress syndrome for lower ARIs), and recurrent or worsening infection within 30 days of follow-up.

${ }^{3}$ Quality of evidence was downgraded one level because of risk of bias: inadequate methods of sequence generation, lack of allocation concealment, and/or lack of blinding of participants.

${ }^{4}$ Quality of evidence was downgraded one level because of inconsistency: heterogeneity in results likely due to differences in the interventions trialled across studies.

${ }^{5}$ Quality of evidence was downgraded one level because of risk of publication bias: review only reported effective interventions.

${ }^{6}$ Quality of evidence was downgraded one level due to imprecision because trials included relatively few patients or when the confidence interval showed substantial variation in the effect of the intervention. 


\section{AP P E N D I CES}

\section{Appendix 1. Search strategies}

\section{MEDLINE}

1 exp Anti-Bacterial Agents/

2 (Antibacterial? or Anti-bacterial? or Antibiotic? or Anti-biotic? or Macrolide? or beta-Lactam? or Antimicrobial? or Anti-microbial? or Penicillin or Methicillin or ampicillin or azithromycin or Cephalexin).tw.

\section{1 or 2}

4 exp Respiratory Tract Infections/ or Nasopharyngitis/ or exp Sinusitis/ or Rhinitis/ or Laryngitis/or Bronchitis/or exp bronchiolitis/ or bronchiolitis, viral/ or exp Pneumonia/ or exp Pleurisy/ or Cough/ or Sneezing/ or exp Otitis Media/ or Earache/ or Influenza, Human/ or Common Cold/

5 (((respiratory or chest) adj3 (infect* or inflam*)) or (ARI or ARTI or URTI or LRTI) or (nasopharyngit* or rhinopharyngit*) or sinusit* or (nasosinusit* or rhinosinusit*) or rhinit* or (rhinorrhoea or rhinorrhea) or ((runny or running or discharg* or congest* or blocked or stuff* or dripping) adj2 (nose* or nasal)) or pharyngit* or sore throat* or (throat* adj3 (inflam* or infect*)) or tonsillit* or laryngit* or croup or (pseudocroup or tracheobronchit* or laryngotracheobronchit $\left.{ }^{\star}\right)$ or (bronchit* or bronchiolit*) or (pneumon* or pleuropneumon* or bronchopneumon ${ }^{\star}$ ) or pleurisy or (cough* or sneez ${ }^{\star}$ ) or (otitis media or aom or ome) or earache* or (influenza* or flu) or common cold ${ }^{\star}$ ).tw.

\section{4 or 5}

7 exp Drug Prescriptions/ or Inappropriate prescribing/ or Practice Patterns, Physicians/

8 (prescrib* or prescrip* or stewardship or Antibiotic therapy or Antibiotic treatment).tw.

97 or 8

10 (Delay or Delayed or Reduce or Reduces or Reducing or Reduced or Discontinue or Stopping).tw.

11 Ambulatory Care/ or exp Ambulatory Care Facilities/ or exp general practice/ or exp general practitioners/ or exp physicians, family/ or exp physicians, primary care/ or exp Primary Health Care/ or exp Office Visits/ or Outpatients/ or exp Emergency Service, Hospital/ or Emergency Medical Services/

12 ((ambulatory adj3 (care or setting? or facilit* or ward? or department? or service?)) or (practi* or physician? or doctor? or Clinician?) or (primary care or primary health care or primary healthcare) or (after hour? or afterhour? or "out of hour?" or ooh) or (clinic? or visit?) or ((health* or medical) adj2 (center? or centre?)) or outpatient? or (emergency adj3 (care or setting? or facilit* or ward? or department? or service?))).tw.

\section{1 or 12}

14 meta-analysis.mp,pt. or review.pt. or search ${ }^{\star} . t w$.

153 and 6 and 9 and 10 and 13 and 14

\section{Embase}

1 exp *antibiotic agent/

2 (Antibacterial? or Anti-bacterial? or Antibiotic? or Anti-biotic? or Macrolide? or beta-Lactam? or Antimicrobial? or Anti-microbial? or Penicillin or Methicillin or ampicillin or azithromycin or Cephalexin).tw.

\section{1 or 2}

4 exp * respiratory tract infection/ or *ear infection/ or exp *otitis media/ or *coughing/ or *sneezing/ or *otalgia/

5 (((respiratory or chest) adj3 (infect* or inflam*)) or (ARI or ARTI or URTI or LRTI) or (nasopharyngit* or rhinopharyngit*) or sinusit ${ }^{\star}$ or (nasosinusit* or rhinosinusit ${ }^{\star}$ ) or rhinit* or (rhinorrhoea or rhinorrhea) or ((runny or running or discharg* or congest* or blocked or stuff ${ }^{\star}$ or dripping) adj2 (nose* or nasal)) or pharyngit* or sore throat* or (throat* adj3 (inflam* or infect $\left.{ }^{\star}\right)$ ) or tonsillit* or laryngit* or croup $^{\star}$ or (pseudocroup or tracheobronchit* or laryngotracheobronchit*) or (bronchit ${ }^{\star}$ or bronchiolit*) or (pneumon* or pleuropneumon* or bronchopneumon $^{\star}$ ) or pleurisy or (cough* or sneez ${ }^{\star}$ ) or (otitis media or aom or ome) or earache* or (influenza* or flu) or common cold ${ }^{\star}$ ).tw.

64 or 5

Clinician-targeted interventions to influence antibiotic prescribing behaviour for acute respiratory infections in primary care: an 
7 * prescription/ or inappropriate prescribing/ or *antibiotic therapy/

8 (prescrib* or prescrip* or stewardship or Antibiotic therapy or Antibiotic treatment).tw.

97 or 8

10 (Delay or Delayed or Reduce or Reduces or Reducing or Reduced or Discontinue or Stopping).tw.

11 ambulatory care/ or outpatient department/ or outpatient/ or general practice/ or general practitioner/ or primary medical care/ or primary health care/ or emergency ward/ or emergency health service/

12 ((ambulatory adj3 (care or setting? or facilit* or ward? or department? or service?)) or (practi* or physician? or doctor? or Clinician?) or (primary care or primary health care or primary healthcare) or (after hour? or afterhour? or "out of hour?" or ooh) or (clinic? or visit?) or ((health* or medical) adj2 (center? or centre?)) or outpatient? or (emergency adj3 (care or setting? or facilit* or ward? or department? or service?))).tw.

1311 or 12

14 meta-analys:.mp. or search:.tw. or review.pt.

153 and 6 and 9 and 10 and 13 and 14

\section{CINAHL}

1 (MH "Antibiotics+")

2 TI ( Antibacterial? or Anti-bacterial? or Antibiotic? or Anti-biotic? or Macrolide? or beta-Lactam? or Antimicrobial? or Anti-microbial? or Penicillin or Methicillin or ampicillin or azithromycin or Cephalexin ) OR AB ( Antibacterial? or Anti-bacterial? or Antibiotic? or Anti-biotic? or Macrolide? or beta-Lactam? or Antimicrobial? or Anti-microbial? or Penicillin or Methicillin or ampicillin or azithromycin or Cephalexin )

3 S1 OR S2

4 (MH "Respiratory Tract Infections+") OR (MH "Otitis Media+") OR (MH "Cough") OR (MH "Sneezing") OR (MH "Earache")

$5 \mathrm{TI}$ ( (((respiratory or chest) N3 (infect* or inflam $\left.{ }^{\star}\right)$ ) or (ARI or ARTI or URTI or LRTI) or (nasopharyngit* or rhinopharyngit*) or sinusit* or (nasosinusit* or rhinosinusit ${ }^{\star}$ ) or rhinit* or (rhinorrhoea or rhinorrhea) or ((runny or running or discharg* or congest* or blocked or stuff $^{\star}$ or dripping) N2 (nose* or nasal)) or pharyngit* or sore throat ${ }^{\star}$ or (throat ${ }^{\star}$ N3 (inflam* or infect $\left.{ }^{\star}\right)$ ) or tonsillit ${ }^{\star}$ or laryngit $^{\star}$ or croup or (pseudocroup or tracheobronchit* or laryngotracheobronchit ${ }^{\star}$ ) or (bronchit ${ }^{\star}$ or bronchiolit*) or (pneumon* or pleuropneumon ${ }^{\star}$ or $^{\star}$ bronchopneumon ${ }^{\star}$ ) or pleurisy or (cough* or sneez ${ }^{\star}$ ) or (otitis media or aom or ome) or earache* or (influenza* or flu) or common cold ${ }^{\star}$ ) ) OR AB ( (((respiratory or chest) N3 (infect* or inflam*)) or (ARI or ARTI or URTI or LRTI) or (nasopharyngit* or rhinopharyngit*) or sinusit* or (nasosinusit* or rhinosinusit*) or rhinit* or (rhinorrhoea or rhinorrhea) or ((runny or running or discharg* or congest* or blocked or stuff* or dripping) N2 (nose* or nasal)) or pharyngit* or sore throat* or (throat ${ }^{\star}$ N3 (inflam ${ }^{\star}$ or infect $\left.{ }^{\star}\right)$ ) or tonsillit* or laryngit ${ }^{\star}$ or croup or (pseudocroup or tracheobronchit* or laryngotracheobronchit ${ }^{\star}$ ) or (bronchit ${ }^{\star}$ or bronchiolit*) or (pneumon ${ }^{\star}$ or pleuropneumon* or bronchopneumon ${ }^{\star}$ ) or pleurisy or (cough ${ }^{\star}$ or sneez ${ }^{\star}$ ) or (otitis media or aom or ome) or earache* or (influenza* or flu) or common cold ${ }^{\star}$ ) )

\section{S4 OR S5}

7 (MH "Prescribing Patterns") OR (MH "Inappropriate Prescribing")

$8 \mathrm{TI}$ ( prescrib* or prescrip* or stewardship or "Antibiotic therapy" or "Antibiotic treatment" ) OR AB ( prescrib* or prescrip* or stewardship or "Antibiotic therapy" or "Antibiotic treatment" )

\section{S7 OR S8}

10 Delay or Delayed or Reduce or Reduces or Reducing or Reduced or Discontinue or Stopping

11 (MH "Ambulatory Care") OR (MM "Ambulatory Care Facilities") OR (MH "Family Practice") OR (MH "Physicians, Family") OR (MH "Physicians, Emergency") OR (MH "Primary Health Care") OR (MH "Emergency Service") OR (MH "Emergency Medicine") OR (MH "Outpatient Service") OR (MH "Outpatients")

12 TI ( ((ambulatory N3 (care or setting? or facilit* or ward? or department? or service?)) or (practi or physician? or doctor? or Clinician?) or (primary care or primary health care or primary healthcare) or (after hour? or afterhour? or "out of hour?" or ooh) or (clinic? or visit?) or ((health* or medical) N2 (center? or centre?)) or outpatient? or (emergency N3 (care or setting? or facilit* or ward? or department? or service?))) ) OR AB ( ((ambulatory N3 (care or setting? or facilit* or ward? or department? or service?)) or (practi* or physician? or doctor? or Clinician?) or (primary care or primary health care or primary healthcare) or (after hour? or afterhour? or "out of hour?" or ooh) or (clinic? or 
visit?) or ((health* or medical) N2 (center? or centre?)) or outpatient? or (emergency N3 (care or setting? or facilit* or ward? or department? or service?))) )

13 S11 OR S12

14 S3 AND S6 AND S9 AND S10 AND S13

15 S3 AND S6 AND S9 AND S10 AND S13 - Limiters - Clinical Queries: Review - Best Balance

\section{Psycinfo}

1 exp antibiotics/

2 (Antibacterial? or Anti-bacterial? or Antibiotic? or Anti-biotic? or Macrolide? or beta-Lactam? or Antimicrobial? or Anti-microbial? or Penicillin or Methicillin or ampicillin or azithromycin or Cephalexin).tw.

31 or 2

4 exp respiratory tract disorders/ or exp influenza/

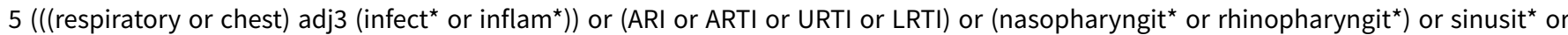
(nasosinusit* or rhinosinusit ${ }^{\star}$ ) or rhinit* or (rhinorrhoea or rhinorrhea) or ((runny or running or discharg* or congest* or blocked or stuff ${ }^{\star}$ or dripping) adj2 (nose* or nasal)) or pharyngit* or sore throat ${ }^{\star}$ or (throat* adj3 (inflam* or infect $\left.{ }^{\star}\right)$ ) or tonsillit* or laryngit* or croup or (pseudocroup or tracheobronchit* or laryngotracheobronchit ${ }^{\star}$ ) or (bronchit* or bronchiolit*) or (pneumon* or pleuropneumon ${ }^{\star}$ or $^{\star}$ bronchopneumon ${ }^{\star}$ ) or pleurisy or (cough ${ }^{\star}$ or sneez ${ }^{\star}$ ) or (otitis media or aom or ome) or earache* or (influenza* or flu) or common cold ${ }^{\star}$ ).tw.

64 or 5

7 exp "prescribing (drugs)"/

8 (prescrib* or prescrip* or stewardship or Antibiotic therapy or Antibiotic treatment).tw.

97 or 8

10 (Delay or Delayed or Reduce or Reduces or Reducing or Reduced or Discontinue or Stopping).tw.

11 outpatient treatment/ or outpatients/ or exp Primary Health Care/ or exp General Practitioners/

12 ((ambulatory adj3 (care or setting? or facilit* or ward? or department? or service?)) or (practi^ or physician? or doctor? or Clinician?) or (primary care or primary health care or primary healthcare) or (after hour? or afterhour? or "out of hour?" or ooh) or (clinic? or visit?) or ((health* or medical) adj2 (center? or centre?)) or outpatient? or (emergency adj3 (care or setting? or facilit* or ward? or department? or service?))).tw.

1311 or 12

14 (control: or effectiveness or risk:).tw.

153 and 6 and 9 and 10 and 13 and 14

\section{Web of Science}

1486,465 TOPIC: (Antibacterial ${ }^{\star}$ or Anti-bacterial ${ }^{\star}$ or Antibiotic ${ }^{*}$ or Anti-biotic ${ }^{*}$ or Macrolide ${ }^{\star}$ or beta-Lactam* or Antimicrobial $^{\star}$ or Antimicrobial* or Penicillin or Methicillin or ampicillin or azithromycin or Cephalexin)

2 415,544 TOPIC: ((((respiratory or chest) NEAR/3 (infect* or inflam $\left.\left.{ }^{\star}\right)\right)$ or ARI or ARTI or URTI or LRTI or nasopharyngit* or rhinopharyngit* or sinusit $^{\star}$ or nasosinusit* or rhinosinusit* or rhinit* or rhinorrhoea or rhinorrhea or ((runny or running or discharg* or congest ${ }^{\star}$ or blocked or stuff* $^{\star}$ or dripping) NEAR/2 (nose* or nasal)) or pharyngit* or "sore throat*" or (throat* NEAR/3 (inflam* or infect*)) or tonsillit* or laryngit* or croup or pseudocroup or tracheobronchit* or laryngotracheobronchit* or bronchit* or bronchiolit* or pneumon* or pleuropneumon* or bronchopneumon ${ }^{\star}$ or pleurisy or cough" or sneez ${ }^{\star}$ or "otitis media" or aom or ome or earache* or influenza* or flu or "common cold ${ }^{\star \prime)}$ )

3 2,388,774 TOPIC: ((ambulatory NEAR/3 (care or setting ${ }^{\star}$ or facilit* or ward ${ }^{\star}$ or department ${ }^{\star}$ or service $\left.{ }^{\star}\right)$ ) or practi ${ }^{\star}$ or physician ${ }^{\star}$ or doctor ${ }^{\star}$ or Clinician* or "primary care" or "primary health care" or "primary healthcare" or "after hour" or afterhour* or "out of hour" or ooh or

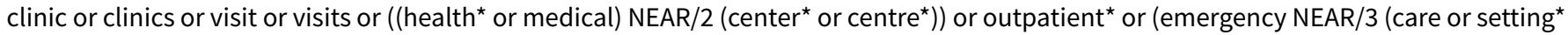
or facilit* or ward* or department ${ }^{\star}$ or service $\left.\left.{ }^{\star}\right)\right)$ )

4 3,612,461 TOPIC: (Delay or Delayed or Reduce or Reduces or Reducing or Reduced or Discontinue or Stopping)

Clinician-targeted interventions to influence antibiotic prescribing behaviour for acute respiratory infections in primary care: an 
5 225,166 TOPIC: (prescrib* or prescrip* or stewardship or "Antibiotic therapy" or "Antibiotic treatment")

6169 (\#5 AND \#4 AND \#3 AND \#2 AND \#1) AND DOCUMENT TYPES: (Review)

7 104,119 (TS=(meta-analysis OR "systematic review" OR search*)) AND DOCUMENT TYPES: (Review)

865 \#7 AND \#5 AND \#4 AND \#3 AND \#2 AND \#1

9169 \#8 OR \#6

Appendix 2. Characteristics of reviews awaiting classification

\begin{tabular}{|c|c|c|c|c|c|}
\hline Review & $\begin{array}{l}\text { Included tri- } \\
\text { als (n) }\end{array}$ & Population & Intervention & $\begin{array}{l}\text { Comparison } \\
\text { intervention }\end{array}$ & $\begin{array}{l}\text { Primary out- } \\
\text { come }\end{array}$ \\
\hline Hu 2016 & 13 & $\begin{array}{l}\text { Children presenting with } \\
\text { upper respiratory infections } \\
\text { in primary care }\end{array}$ & $\begin{array}{l}\text { Approaches targeting clini- } \\
\text { cians or parents of child pa- } \\
\text { tients, or both }\end{array}$ & Usual care & $\begin{array}{l}\text { Antibiotic pre- } \\
\text { scribing }\end{array}$ \\
\hline $\begin{array}{l}\text { Martinez-Gon- } \\
\text { zalez } 2017 \\
\text { (protocol on- } \\
\text { ly) }\end{array}$ & Unknown & $\begin{array}{l}\text { Adults and children pre- } \\
\text { senting in primary care with } \\
\text { respiratory tract infections }\end{array}$ & $\begin{array}{l}\text { Any intervention aimed at im- } \\
\text { proving the quality of prescrib- } \\
\text { ing and use of antibiotics in } \\
\text { primary care patients with res- } \\
\text { piratory tract infections }\end{array}$ & Unknown & $\begin{array}{l}\text { Antibiotic pre- } \\
\text { scribing and } \\
\text { use }\end{array}$ \\
\hline $\begin{array}{l}\text { McDonagh } \\
2016\end{array}$ & $\begin{array}{l}88 \text { ran- } \\
\text { domised con- } \\
\text { trolled trials }\end{array}$ & $\begin{array}{l}\text { Adult or child patients pre- } \\
\text { senting with acute respira- } \\
\text { tory tract infections }\end{array}$ & $\begin{array}{l}\text { Any intervention designed to } \\
\text { improve antibiotic use aimed } \\
\text { at clinicians, patients, or the } \\
\text { public }\end{array}$ & $\begin{array}{l}\text { Usual care or } \\
\text { alternative in- } \\
\text { tervention }\end{array}$ & $\begin{array}{l}\text { Antibiotic pre- } \\
\text { scribing and } \\
\text { use }\end{array}$ \\
\hline $\begin{array}{l}\text { O'Sullivan } \\
2016\end{array}$ & 2 & $\begin{array}{l}\text { Adults or children present- } \\
\text { ing with acute upper respi- } \\
\text { ratory tract infection in pri- } \\
\text { mary care }\end{array}$ & $\begin{array}{l}\text { Written information for pa- } \\
\text { tients (or parents of child pa- } \\
\text { tients) }\end{array}$ & $\begin{array}{l}\text { Usual care or } \\
\text { alternative in- } \\
\text { tervention }\end{array}$ & $\begin{array}{l}\text { Antibiotic pre- } \\
\text { scribing and } \\
\text { use }\end{array}$ \\
\hline
\end{tabular}

Appendix 3. Initial ROBIS quality assessment on 11 reviews for potential inclusion in the overview

\begin{tabular}{|c|c|c|c|c|c|}
\hline \multirow[t]{3}{*}{ Review ID } & \multicolumn{5}{|c|}{ ROBIS assessment } \\
\hline & \multicolumn{4}{|c|}{ Phase 2 domains } & \multirow{2}{*}{$\begin{array}{l}\text { Phase } 3 \\
\text { 5. Risk of bias }\end{array}$} \\
\hline & $\begin{array}{l}\text { 1. Study eligi- } \\
\text { bility criteria }\end{array}$ & $\begin{array}{l}\text { 2. Identifi- } \\
\text { cation and } \\
\text { selection of } \\
\text { studies }\end{array}$ & $\begin{array}{l}\text { 3. Data col- } \\
\text { lection and } \\
\text { study ap- } \\
\text { praisal }\end{array}$ & $\begin{array}{l}\text { 4. Synthesis } \\
\text { and findings }\end{array}$ & \\
\hline $\begin{array}{l}\text { Aabenhus } \\
2014\end{array}$ & Low risk & Low risk & Low risk & Low risk & Low risk \\
\hline Arnold 2005 & Low risk & Low risk & Low risk & $\begin{array}{l}\text { High risk } \\
4.6 \text { - Quality of } \\
\text { studies is not } \\
\text { assessed in any } \\
\text { analysis. }\end{array}$ & $\begin{array}{l}\text { Low risk } \\
\text { A. Interpretation of findings addressed all } \\
\text { concerns. } \\
\text { B. Relevance of identified studies was ap- } \\
\text { propriately considered. }\end{array}$ \\
\hline
\end{tabular}


C. Review authors avoided emphasising results on the basis of their statistical significance.

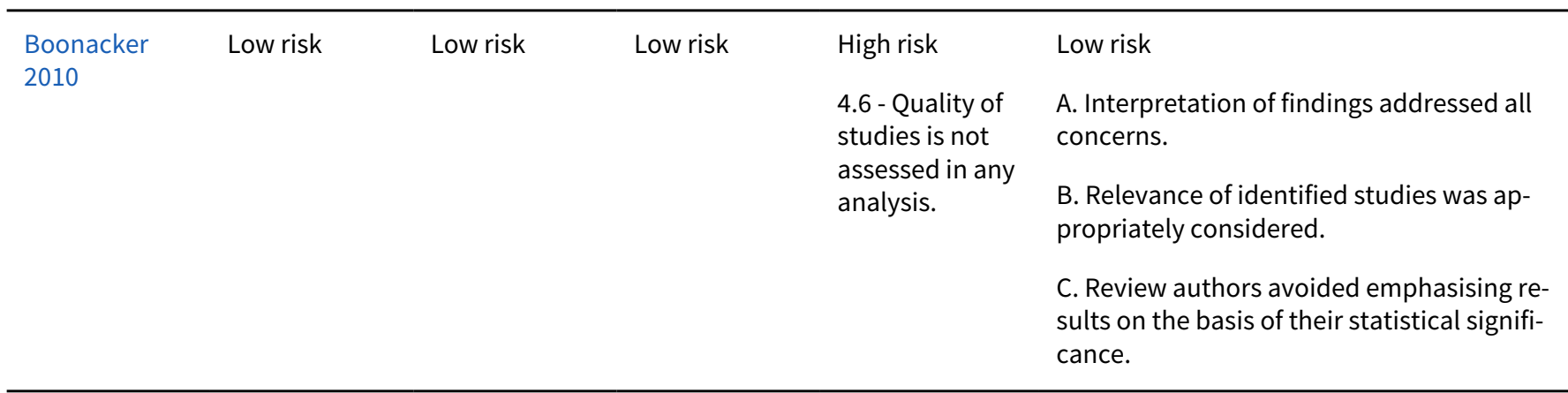

\begin{tabular}{|c|c|c|c|c|c|}
\hline \multirow[t]{3}{*}{ Coxeter 2015} & Low risk & Low risk & Low risk & High risk & Low risk \\
\hline & & & & $\begin{array}{l}4.6 \text { - Quality of } \\
\text { studies is not } \\
\text { assessed in any } \\
\text { analysis. }\end{array}$ & $\begin{array}{l}\text { A. Interpretation of findings addressed all } \\
\text { concerns. } \\
\text { B. Relevance of identified studies was ap- } \\
\text { propriately considered. }\end{array}$ \\
\hline & & & & & $\begin{array}{l}\text { C. Review authors avoided emphasising re- } \\
\text { sults on the basis of their statistical signifi- } \\
\text { cance. }\end{array}$ \\
\hline
\end{tabular}

\begin{tabular}{|c|c|c|c|c|c|}
\hline de Bont 2015 & Low risk & Low risk & Low risk & $\begin{array}{l}\text { High risk } \\
4.6 \text { - Quality of } \\
\text { studies is not } \\
\text { assessed in any } \\
\text { analysis. }\end{array}$ & $\begin{array}{l}\text { Low risk } \\
\text { A. Interpretation of findings addressed all } \\
\text { concerns. } \\
\text { B. Relevance of identified studies was ap- } \\
\text { propriately considered. } \\
\text { C. Review authors avoided emphasising re- } \\
\text { sults on the basis of their statistical signifi- } \\
\text { cance. }\end{array}$ \\
\hline Doan 2014 & Low risk & Low risk & Low risk & Low risk & Low risk \\
\hline Huang 2013 & Low risk & Low risk & Low risk & $\begin{array}{l}\text { High risk } \\
4.5 \text { - No funnel } \\
\text { plots or sensi- } \\
\text { tivity analysis } \\
\text { presented. } \\
4.6 \text { - Quality of } \\
\text { studies is not } \\
\text { assessed in any } \\
\text { analysis. }\end{array}$ & $\begin{array}{l}\text { Low risk } \\
\text { A. Interpretation of findings addressed all } \\
\text { concerns. } \\
\text { B. Relevance of identified studies was ap- } \\
\text { propriately considered. } \\
\text { C. Review authors avoided emphasising re- } \\
\text { sults on the basis of their statistical signifi- } \\
\text { cance. }\end{array}$ \\
\hline
\end{tabular}

\begin{tabular}{|c|c|c|c|c|c|}
\hline \multirow[t]{2}{*}{ Ranji 2008} & High risk & High risk & High risk & High risk & High risk \\
\hline & $\begin{array}{l}1.5 \text { - Non-Eng- } \\
\text { lish studies } \\
\text { were exclud- } \\
\text { ed. }\end{array}$ & $\begin{array}{l}2.4 \text { - Non-Eng- } \\
\text { lish studies } \\
\text { were exclud- } \\
\text { ed. }\end{array}$ & $\begin{array}{l}3.4 \text { - Review } \\
\text { authors pro- } \\
\text { vided an as- } \\
\text { sessment of } \\
\text { study qual- } \\
\text { ity but not }\end{array}$ & $\begin{array}{l}4.5 \text { - No funnel } \\
\text { plots or sensi- } \\
\text { tivity analysis } \\
\text { presented. } \\
4.6 \text { - Bias in } \\
\text { studies is not }\end{array}$ & $\begin{array}{l}\text { A. Review authors do not discuss exclusion } \\
\text { of non-English studies as a limitation. Re- } \\
\text { view authors do not discuss risk of bias or } \\
\text { limitations in assessment of study quality. } \\
\text { Assessment of study quality is unclear. Re- }\end{array}$ \\
\hline
\end{tabular}

Clinician-targeted interventions to influence antibiotic prescribing behaviour for acute respiratory infections in primary care: an 


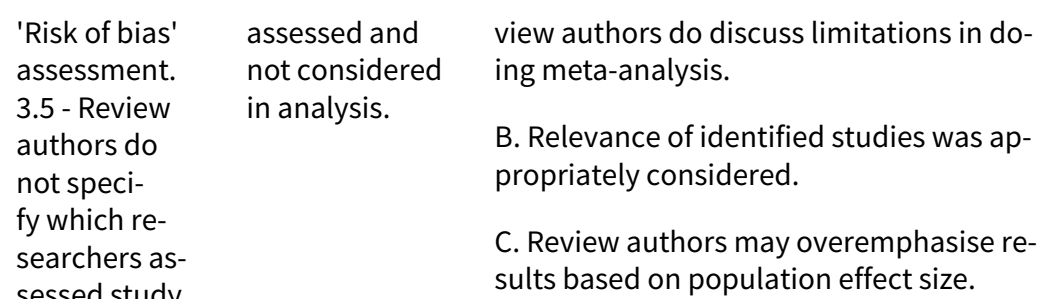
quality.

\begin{tabular}{|c|c|c|c|c|c|}
\hline Schuetz 2012 & Low risk & Low risk & Low risk & Low risk & Low risk \\
\hline \multirow{4}{*}{$\begin{array}{l}\text { van der Does } \\
2016\end{array}$} & High risk & High risk & High risk & High risk & High risk \\
\hline & \multirow[t]{3}{*}{$\begin{array}{l}1.5 \text { - Non-Eng- } \\
\text { lish studies } \\
\text { were exclud- } \\
\text { ed. }\end{array}$} & $\begin{array}{l}2.2 \text { - No other } \\
\text { search meth- } \\
\text { ods in addi- } \\
\text { tion to data- } \\
\text { bases were } \\
\text { used to identi- } \\
\text { fy reports. }\end{array}$ & $\begin{array}{l}3.1 \text { - Review } \\
\text { authors do } \\
\text { not speci- } \\
\text { fy which re- } \\
\text { searchers per- } \\
\text { formed data } \\
\text { extraction. }\end{array}$ & \multirow[t]{3}{*}{$\begin{array}{l}4.6 \text { - Quality of } \\
\text { studies is not } \\
\text { assessed in any } \\
\text { analysis. }\end{array}$} & $\begin{array}{l}\text { A. Review authors do not discuss exclusion } \\
\text { of non-English studies or not using oth- } \\
\text { er methods to search for papers as limita- } \\
\text { tions. Review authors did not comment on } \\
\text { methods of data extraction or quality as- } \\
\text { sessment as potential limitations. Review } \\
\text { authors do discuss 'Risk of bias' assess- } \\
\text { ment. }\end{array}$ \\
\hline & & $\begin{array}{l}2.4 \text { - Non-Eng- } \\
\text { lish studies } \\
\text { were exclud- } \\
\text { ed. }\end{array}$ & $\begin{array}{l}3.5 \text { - Review } \\
\text { authors do } \\
\text { not speci- } \\
\text { fy which re- }\end{array}$ & & $\begin{array}{l}\text { B. Relevance of identified studies was ap- } \\
\text { propriately considered. }\end{array}$ \\
\hline & & & $\begin{array}{l}\text { searchers per- } \\
\text { formed qual- } \\
\text { ity assess- } \\
\text { ment. }\end{array}$ & & $\begin{array}{l}\text { C. Review authors avoided emphasising re- } \\
\text { sults on the basis of their statistical signifi- } \\
\text { cance. }\end{array}$ \\
\hline \multirow[t]{4}{*}{ Vodicka 2013} & High risk & High risk & Low risk & High risk & High risk \\
\hline & \multirow{3}{*}{$\begin{array}{l}1.5 \text { - Search } \\
\text { was limited } \\
\text { to studies } \\
\text { conducted in } \\
\text { high-income } \\
\text { countries on- } \\
\text { ly, for which } \\
\text { a reason was } \\
\text { not provided. }\end{array}$} & $\begin{array}{l}2.1 \text { - Only pub- } \\
\text { lished studies } \\
\text { were includ- } \\
\text { ed. }\end{array}$ & & \multirow[t]{3}{*}{$\begin{array}{l}4.6 \text { - Quality of } \\
\text { studies is not } \\
\text { assessed in any } \\
\text { analysis. }\end{array}$} & $\begin{array}{l}\text { A. Review authors acknowledge focus on } \\
\text { high-income countries and published stud- } \\
\text { ies in their limitations section. Review au- } \\
\text { thors do not discuss data screening by } 1 \\
\text { author. }\end{array}$ \\
\hline & & $\begin{array}{l}2.5-\text { On- } \\
\text { ly } 1 \text { author } \\
\text { screened titles } \\
\text { and abstracts. }\end{array}$ & & & $\begin{array}{l}\text { B. Relevance of identified studies was ap- } \\
\text { propriately considered. }\end{array}$ \\
\hline & & & & & $\begin{array}{l}\text { C. Review authors avoided emphasising re- } \\
\text { sults on the basis of their statistical signifi- } \\
\text { cance. }\end{array}$ \\
\hline
\end{tabular}

WHAT'S NEW

\begin{tabular}{lll}
\hline Date & Event & Description \\
\hline 11 September 2019 & Amended & $\begin{array}{l}\text { A review author (CCB) amended his declaration of interest state- } \\
\text { ment in response to a request by the Cochrane Funding Arbiter. } \\
\end{array}$ \\
& $\begin{array}{l}\text { The Funding Arbiter did not consider research grants received to } \\
\text { be a Clause } 1 \text { (funding) breach, but because point of care tests } \\
\text { are included as interventions of interest, the grants were deter- } \\
\text { mined to be relevant and were declared. }\end{array}$ \\
\hline
\end{tabular}




\section{HISTORY}

Protocol first published: Issue 6, 2016

Review first published: Issue 9, 2017

\begin{tabular}{lll}
\hline Date & Event & Description \\
\hline 30 August 2017 & New search has been performed & $\begin{array}{l}\text { We re-ran the search on 19 May 2017, screened the results and } \\
\text { placed the three reviews that we identified from this updated } \\
\text { search in Appendix 2: Characteristics of reviews awaiting classi- } \\
\text { fication. We will incorporate these reviews in the next version of } \\
\text { this overview, as appropriate. }\end{array}$ \\
\end{tabular}

\section{CONTRIBUTIONS OF AUTHORS}

STC, OVH, KW, AMCC, MPH, NR, CCB, and CDM contributed to and wrote the original protocol for the overview. NR developed and ran the search strategy. STC, OVH, and AMCC screened the abstracts and full texts to assess the eligibility of studies. STC, PST, and MPH extracted data from the included reviews and performed the quality assessment. STC led the writing of the overview, and all other authors commented on and contributed to sequential drafts and approved the final version.

\section{DECLARATIONS OF INTEREST}

Sarah Tonkin-Crine is a health psychologist funded by the NIHR Health Protection Research Unit in Healthcare Associated Infections and Antimicrobial Resistance at the University of Oxford in partnership with Public Health England.

Pui San Tan is an infectious diseases and acute care postdoctoral researcher funded by the NIHR under its Programme Grants for Applied Research Programme (RP-PG- 0514-20015).

Oliver van Hecke is a general practitioner and clinical research fellow at the University of Oxford, funded by the NIHR under its Programme Grants for Applied Research Programme (RP-PG-1210-12012).

Kay Wang is a NIHR postdoctoral fellow at the University of Oxford.

Nia Roberts: none known.

Amanda McCullough is a postdoctoral fellow at the Centre for Research Excellence in Minimising Antibiotic Resistance from Acute Respiratory Infections (CREMARA) funded by the National Health and Medical Research Council (NHMRC), Australia (1044904).

Malene Plejdrup Hansen was a postdoctoral fellow at the Centre for Research Excellence in Minimising Antibiotic Resistance from Acute Respiratory Infections (CREMARA) funded by the National Health and Medical Research Council (NHMRC), Australia (1044904), and is a senior research fellow at the Research Unit for General Practice in Aalborg funded by the Research Foundation of General Practice in Denmark.

Christopher C Butler has held research grants to develop, evaluate and implement antibiotic stewardship interventions. He has received honoraria from Alere and Roche for contributions about point of care diagnostics. The honorarium from Roche did not relate to this review in any way. He is the chief investigator of the publicly funded PACE study that is assessing C-reactive protein point of care testing (CRP POCT) to guide antibiotic treatment for acute exacerbations of chronic obstructive airways disease. Alere has provided the CRP POCT devices and associated support as an unconditional educational grant free to the study. He also receives support from the NIHR Health Protection Research Unit in Healthcare Associated Infections and Antimicrobial Resistance at the University of Oxford, and holds several publicly funded grants to conduct research in the field of infections. No commercial funding was received from any source to conduct this review.

Chris B Del Mar is co-ordinating editor of the Cochrane Acute Respiratory Infections Group and chief investigator at the Centre for Research Excellence in Minimising Antibiotic Resistance from Acute Respiratory Infections (CREMARA) funded by the National Health and Medical Research Council (NHMRC), Australia (1044904). He received royalties from BMJ Books and Elsevier for activities unrelated to this submitted work. 


\section{SOURCES OF SUPPORT}

\section{Internal sources}

- Bond University, Gold Coast, Australia.

- University of Oxford, Oxford, UK.

\section{External sources}

- National Institute of Health Research (NIHR), UK.

Health Protection Research Unit in Healthcare Associated Infections and Antimicrobial Resistance at the University of Oxford; Programme Grants for Applied Research Programme (RP-PG-1210-12012).

- National Health and Medical Research Council (1044904), Australia.

\section{NDEX TERMS}

\section{Medical Subject Headings (MeSH)}

*Primary Health Care; *Review Literature as Topic; Acute Disease; Anti-Bacterial Agents [ ${ }^{\star}$ therapeutic use]; C-Reactive Protein [analysis]; Calcitonin [blood]; Drug Resistance, Bacterial; Inappropriate Prescribing [prevention \& control]; Publication Bias; Randomized Controlled Trials as Topic; Respiratory Tract Infections [blood] [ ${ }^{\star}$ drug therapy] [virology]; Virus Diseases [diagnosis]

\section{MeSH check words}

Humans 